\title{
Excesso de Confiança, Otimismo Gerencial e os Determinantes da Estrutura de Capital
}

\author{
Lucas Ayres B. de C. Barros* \\ Alexandre Di Miceli da Silveira**
}

\section{Resumo}

Este estudo investiga os determinantes da estrutura de capital das empresas introduzindo uma perspectiva comportamental ainda pouco explorada na literatura da área. De um conjunto de teorias recentemente desenvolvidas, deriva-se a seguinte predição central: empresas geridas por indivíduos otimistas e/ou excessivamente confiantes serão mais relativamente endividadas do que as demais, ceteris paribus. Propõe-se diferentes proxies para o otimismo/excesso de confiança baseadas no status do gestor como "empreendedor" ou "não-empreendedor", proposição esta respaldada por teorias e sólida evidência empírica, bem como no padrão de posse de ações da própria empresa por parte do seu gestor. $\mathrm{O}$ trabalho inclui, ainda, os candidatos a determinantes utilizados previamente na literatura sobre estrutura de capital no Brasil e no exterior. A amostra compõe-se de 153 empresas com ações negociadas na Bovespa e com dados disponíveis entre 1998 e 2003 . A análise empírica sugere que as proxies para os referidos vieses cognitivos figuram entre os principais determinantes da estrutura de financiamento. Também se mostraram relevantes, em maior ou menor grau, os indicadores de lucratividade, tamanho, pagamento de dividendos e tangibilidade, bem como algumas variáveis que capturam os padrões de governança corporativa das empresas. Os resultados aqui reportados sugerem que abordagens comportamentais baseadas nas pesquisas sobre a psicologia humana podem oferecer uma contribuição relevante para a compreensão dos direcionadores das principais decisões corporativas.

Palavras-chave: estrutura de capital; finanças comportamentais; vieses cognitivos; excesso de confiança; otimismo; finanças corporativas.

Códigos JEL: G30; G31; G32.

\section{Abstract}

This research examines the determinants of the capital structure of firms introducing a behavioral perspective that has received little attention in corporate finance literature. The following central hypothesis emerges from a set of recently developed theories: firms managed by optimistic and/or overconfident people will choose more levered financing structures than others, ceteris paribus. We propose different proxies for optimism/overconfidence, based on the manager's status as an entrepreneur or non-entrepreneur, an idea that is supported

Submetido em Outubro de 2007. Aceito em Novembro de 2008. O artigo foi avaliado segundo o processo de duplo anonimato além se de ser avaliado pelo editor. Editor responsável: Jairo Procianoy.

*Professor do Centro de Ciências e Aplicadas da Universidade Prebisteriana Mackenzie (CCSA/Mackenzie) e da Faculdade de Economia, Administração e Contabilidade da Universidade de São Paulo (FEA/USP). E-mail: lucasayres2002@gmail.com

**Professor da Faculdade de Economia, Administração e Contabilidade da Universidade de São Paulo (FEA/USP). E-mail: alexfea@usp.br 
by theories and solid empirical evidence, as well as on the pattern of ownership of the firm's shares by its manager. The study also includes potential determinants of capital structure used in earlier research. We use a sample of Brazilian firms listed in the Sao Paulo Stock Exchange (Bovespa) in the years 1998 to 2003. The empirical analysis suggests that the proxies for the referred cognitive biases are important determinants of capital structure. We also found as relevant explanatory variables: profitability, size, dividend payment and tangibility, as well as some indicators that capture the firms' corporate governance standards. These results suggest that behavioral approaches based on human psychology research can offer relevant contributions to the understanding of corporate decision making.

Keywords: capital structure; behavioral finance; cognitive bias; overconfidence; optimism; corporate finance.

\section{Introdução}

As pesquisas que enfocam os direcionadores das decisões de financiamento das empresas abordam o problema utilizando uma miríade de pontos de vista diferentes. Não obstante, de forma geral eles compartilham a suposição implícita de que os participantes dos mercados financeiros e também os gestores das empresas agem sempre de forma perfeitamente racional. Uma vasta e crescente literatura sobre psicologia e comportamento humanos revela, porém, que a maior parte dos indivíduos, incluindo investidores e gestores de empresas, apresenta importantes limites em seus processos cognitivos e tende a desenvolver vieses de comportamento capazes de influenciar de forma significativa seus processos decisórios. É possível, em particular, que alguns dentre os vieses cognitivos catalogados impactem significativamente as principais decisões corporativas.

Este trabalho investiga a possível influência de dois vieses de cognição estreitamente relacionados entre si e fartamente registrados em pesquisas comportamentais, os vieses do otimismo e do excesso de confiança, sobre as decisões de estrutura de capital das empresas. Uma recente literatura teórica inscrita no campo de Finanças Comportamentais sugere que tais vieses, freqüentemente observados em gestores de empresas, podem influenciar materialmente as decisões de investimento e de financiamento dos mesmos. Em particular, a seguinte predição emerge destes argumentos: gestores otimistas e/ou excessivamente confiantes (ou, por simplicidade, "enviesados") optarão por níveis de endividamento relativo para suas empresas mais elevados do que aqueles que escolheriam se fossem "racionais" (ou não-enviesados). Intuitivamente, esta propensão ao endividamento é motivada pela tendência dos gestores enviesados a superestimar a capacidade de endividamento de sua empresa, na medida em que subestimam seu risco de falência ou de enfrentar dificuldades financeiras. Logo, estes vieses figurariam entre os determinantes da estrutura de financiamentos das empresas.

A presente pesquisa oferece um dos primeiros testes desta hipótese, propondo estratégias inovadoras para identificar empiricamente a presença dos vieses de interesse. Com base em sólidas evidências empíricas provenientes de estudos experimentais e não-experimentais e apoiadas por análises teóricas, argumenta-se que 
indivíduos que gerem o seu próprio negócio são substancialmente mais propensos, em média, a mostrar excesso de confiança e otimismo em seu processo decisório do que gestores profissionais. De fato, é provável que o otimismo e a confiança exacerbada destes indivíduos os tenha motivado a se tornarem empreendedores em primeiro lugar. Desta forma, a classificação dos gestores como "empreendedores" e "não-empreendedores" é utilizada como base para a construção de diferentes proxies que visam a identificar empiricamente os referidos vieses. Para verificar a robustez dos resultados, também são utilizadas no trabalho proxies alternativas baseadas na posse de ações da própria empresa por parte do seu principal gestor. Argumenta-se, neste caso, que a sub-diversificação da carteira pessoal do gestor correlaciona-se, pelo menos parcialmente, com seu grau de otimismo e excesso de confiança.

Utilizando dados entre 1998 e 2003 de uma amostra de empresas brasileiras com ações negociadas na Bovespa, foram estimados modelos dinâmicos e estáticos relacionando o nível de alavancagem das empresas com as proxies para os vieses cognitivos e para outros potenciais determinantes da estrutura de capital investigados em trabalhos anteriores. Como contribuição metodológica, estes modelos foram estimados por meio de procedimentos robustos baseados no Método dos Momentos Generalizado. Argumenta-se que estes estimadores são capazes de mitigar problemas de endogeneidade relevantes para pesquisas do gênero.

Os resultados da análise empírica revelam uma significativa influência positiva das proxies para otimismo/excesso de confiança gerencial sobre o nível de alavancagem das empresas da amostra, depois de isoladas fontes observáveis e nãoobserváveis de heterogeneidade entre as empresas. Embora deva ser interpretada com cautela, em face da natureza indireta da mensuração dos vieses cognitivos, esta evidência oferece suporte à hipótese testada e sugere que vieses cognitivos podem influenciar significativamente as decisões de financiamento corporativas. Adicionalmente, os resultados apontam como variáveis relevantes para explicar o comportamento da alavancagem os indicadores de lucratividade, tamanho, pagamento de dividendos e tangibilidade, bem como algumas variáveis que capturam os padrões de governança corporativa das empresas.

O artigo está estruturado da seguinte forma: a Seção 2 apresenta a fundamentação teórica da pesquisa. A Seção 3 traz o método do estudo empírico. A Seção 4 discute os principais resultados obtidos e a Seção 5 apresenta as considerações finais do trabalho. 


\section{Fundamentação Teórica}

\subsection{Otimismo e excesso de confiança}

Segundo De Bondt e Thaler (1995, p. 389): "Talvez a descoberta mais robusta da psicologia do julgamento seja que as pessoas são excessivamente confiantes". ${ }^{1}$ Mesmo Mark Rubinstein (2001, p. 17), um eminente pesquisador defensor do paradigma da racionalidade em Finanças, afirma: "[...] eu tenho por muito tempo acreditado que os investidores são excessivamente confiantes. Com certeza, o investidor médio acredita que é mais esperto do que o investidor médio". ${ }^{2}$ Computam-se hoje centenas de trabalhos de psicólogos e outros pesquisadores do comportamento humano sobre este fenômeno cognitivo e sobre outro estreitamente relacionado, o otimismo em excesso.

$\mathrm{O}$ excesso de confiança foi identificado em diferentes contextos comportamentais. Dois estudos experimentais pioneiros foram apresentados por Alpert e Raiffa (1982) e Fischhoff (1977). Os autores verificaram que os participantes dos seus experimentos tenderam a confiar exageradamente na precisão de suas estimativas subjetivas sobre quantidades incertas, acreditando que estavam corretos com muito mais freqüência do que efetivamente estavam. Estudos como estes fomentaram outras pesquisas que mostraram a tendência à confiança excessiva na forma de erros de calibração de probabilidades (vide Lichtenstein et alii (1982), Brenner et alii (1996).

O excesso de confiança também pode ser associado mais genericamente à tendência das pessoas a superestimar suas próprias habilidades e conhecimentos e/ou a qualidade e precisão das informações que são capazes de obter. Os estudos sobre as chamadas "ilusões positivas" mostram que as pessoas tendem a se considerar melhores do que as outras ou acima da média em diversos atributos, sejam sociais, morais (elas se julgam mais justas do que as demais) ou de habilidade propriamente dita, como é o caso da crença da maior parte dos motoristas na superioridade de sua habilidade ao volante (Svenson, 1981, Taylor e Brown, 1988, Alicke et alii, 1995).

Uma outra linha de pesquisas focalizou o viés do otimismo, estreitamente relacionado ao excesso de confiança. Alguns dos trabalhos pioneiros são atribuídos a Weinstein $(1980,1982)$. Os participantes dos seus experimentos consistentemente julgaram que as suas probabilidades de passar por experiências positivas durante a vida são superiores à média, ou seja, são maiores do que as probabilidades de sucesso que eles associam a seus pares. Simetricamente, os participantes consideraram inferiores à média as suas chances de passar por experiências negativas em geral e, em particular, eles tenderam a subestimar a sua suscetibilidade a problemas de saúde. Kunda (1987) oferece outras evidências de otimismo na população em geral.

\footnotetext{
${ }^{1}$ Tradução livre do autor.

${ }^{2}$ Tradução livre do autor.
} 
Há boas razões para se supor que os administradores de empresas e empreendedores são particularmente suscetíveis aos vieses da confiança excessiva e do otimismo. Primeiramente, uma vez que os indivíduos em geral tendem a superestimar as suas próprias habilidades eles tenderão a mostrar maior excesso de confiança e otimismo em relação a resultados incertos que pensam poder controlar (Weinstein, 1980). March e Shapira (1987), por sua vez, argumentam que os gestores das empresas, após selecionarem os projetos de investimento que serão por eles empreendidos, tornam-se vítimas freqüentes da chamada "ilusão do controle", minimizando inapropriadamente as probabilidades de fracasso da empreitada. Ademais, Fischhoff et alii (Op. cit.) e Lichtenstein et alii (Op. cit.), dentre outros, reportam que o excesso de confiança revelado nos experimentos é geralmente maior quando os participantes respondem a questões de dificuldade moderada ou elevada. De fato, o fenômeno do excesso de confiança tende a desaparecer ou mesmo a ser invertido (confiança excessivamente reduzida) quando as questões apresentadas são muito fáceis e as tarefas envolvidas são bastante previsíveis, repetitivas e sobre os seus resultados há feedback rápido e preciso. As principais decisões corporativas, a exemplo da seleção de projetos de investimento, certamente se enquadram na categoria das tarefas de alta complexidade e feedback lento e freqüentemente ambíguo.

Pessoas excessivamente confiantes em suas habilidades e na precisão dos seus julgamentos minimizam os riscos inerentes às tarefas que empreendem e por isso tendem a mostrar um desempenho acentuadamente positivo ou acentuadamente negativo. Aqueles que obtêm sucesso destacado dentro das organizações ou em seus empreendimentos próprios acabam por se consolidar como membros da alta gestão. Utilizando este raciocínio, Goel e Thakor (2002) modelam o processo de escolha de líderes dentro de organizações. Uma conclusão de sua análise é que a competição pela liderança induz os candidatos a tomarem decisões mais arriscadas. Neste contexto, candidatos excessivamente confiantes levam vantagem sobre seus pares racionais e têm maior probabilidade de alcançar o posto mais importante da empresa. Logo, gestores excessivamente confiantes não só podem sobreviver no ambiente corporativo como podem prosperar e tomar espaço dos gestores racionais menos ousados.

Além disso, um outro viés bem documentado na literatura psicológica, conhecido como viés da auto-atribuição (Miller e Ross, 1975, Nisbett e Ross, 1980), induz as pessoas a atribuírem a si mesmas uma parcela excessivamente grande dos créditos por eventuais sucessos em seus empreendimentos e excessivamente pequena da responsabilidade por eventuais fracassos. Este viés de aprendizado foi utilizado como pressuposto no modelo de Gervais e Odean (2001), os quais sugerem que investidores dos mercados financeiros que experimentaram seqüências recentes de sucessos tendem a ficar ainda mais excessivamente confiantes nas suas próprias habilidades e conhecimentos. Este raciocínio pode ser aplicado no caso corporativo para sustentar a hipótese de que administradores que conseguiram galgar posições até chegarem à alta gestão da empresa possivelmente tornaram-se 
excessivamente confiantes no processo por atribuírem de forma exagerada seus sucessos à sua própria competência (Gervais et alii, 2003).

Gervais et alii (Ibid.) argumentam, ainda, que os gestores podem ser mais excessivamente confiantes do que a população em geral em razão de um viés de seleção. Para os autores, as pessoas mais confiantes e otimistas sobre suas perspectivas profissionais têm mais chances de se candidatarem aos concorridos postos de alta gestão. Por sua vez, as empresas também podem selecionar pessoas com estas características se associarem a aparência de confiança e otimismo à maior habilidade do candidato ou mesmo se racionalmente preferirem candidatos com estes vieses, como sugere o modelo desenvolvido pelos mesmos autores.

\subsection{Otimismo, excesso de confiança e estrutura de capital}

As implicações para as principais decisões corporativas dos vieses do otimismo e do excesso de confiança apenas começam a ser exploradas pelos pesquisadores de Finanças Comportamentais. Diversos trabalhos enfocam o problema do ponto de vista de gestores racionais que interagem com investidores externos excessivamente confiantes. Só mais recentemente surgiram, em menor número, análises enfocando os vieses cognitivos dos próprios gestores e procurando entender de que maneira eles podem afetar suas decisões de investimento e de financiamento. Uma extensa revisão desta literatura é oferecida por Baker et alii (2004).

Genericamente, conforme discutido acima, a literatura psicológica e comportamental permite associar o viés do otimismo a uma percepção exageradamente positiva da probabilidade de ocorrência de eventos favoráveis e, simetricamente, à subestimação da probabilidade de ocorrência de eventos desfavoráveis. Por seu turno, a confiança excessiva associa-se à superestimação da qualidade e precisão das informações (sinais acerca de possibilidades futuras) disponíveis para o indivíduo ou, analogamente, à subestimação da volatilidade de processos que envolvem incerteza. No mesmo espírito, o excesso de confiança pode levar o indivíduo a pensar que é mais competente e habilidoso do que os demais ou, genericamente, que está "acima da média".

No modelo de Heaton III (2002), um dos pioneiros neste campo, gestores otimistas acreditam que os projetos disponíveis para suas empresas são melhores (em termos de retorno esperado) do que eles são na verdade e por isso julgam que os títulos por elas emitidos, sejam dívidas ou ações, são sistematicamente subavaliados pelo mercado (o modelo assume que o mercado de capitais é eficiente). Por serem menos protegidas contratualmente, as ações serão os títulos mais sujeitos à desvalorização do ponto de vista gerencial. Como conseqüência, a empresa preferirá financiar seus projetos de investimento com recursos gerados internamente e em segundo lugar através da emissão de títulos de dívida, recorrendo apenas em último caso à emissão de novas ações.

Estes resultados são compatíveis com a teoria da pecking order. Diferentemente da proposição original de Myers (1984) e Myers (1984), não obstante, a análise de Heaton III (Op. cit.) prevê que a hierarquização dos tipos de financi- 
amento será mais pronunciada quanto mais otimista for o gestor, ceteris paribus. Uma predição similar é oferecida pelas análises de Malmendier e Tate $(2002,2003)$ e Fairchild (2005), ambos modelando o otimismo de forma análoga à proposta por Heaton III (Op. cit.).

Quando o excesso de confiança, refletindo-se na percepção enviesada da volatilidade dos resultados futuros do empreendimento, é acrescido à análise, entretanto, a hierarquização de preferências por fontes de financiamento pode desaparecer, como mostra o modelo analiticamente mais completo de Hackbarth (2004). De fato, a emissão de ações pode se tornar, em certas circunstâncias, a fonte preferencial de financiamento. Em outras palavras, as empresas geridas por indivíduos otimistas e simultaneamente confiantes em excesso não necessariamente seguirão uma pecking order, embora isso possa acontecer, dependendo da preponderância de um ou de outro viés. Logo, considerado o conjunto das teorias, a hierarquização das fontes de financiamento não está implicada pelo enviesamento cognitivo dos gestores.

Por outro lado, um resultado teórico relativo às decisões de financiamento das empresas é compatível com todos os modelos disponíveis na literatura e emerge como predição central deste corpo teórico, qual seja, gestores cognitivamente enviesados, no sentido do otimismo e/ou do excesso de confiança, superestimarão a capacidade de endividamento da empresa. Intuitivamente, no modelo de Hackbarth (Ibid.) isto ocorre porque o gestor enviesado acredita que as perspectivas do negócio são melhores do que realmente são e também que o risco de falência da empresa é menor do que o risco verdadeiro. Neste caso, sua percepção do custo esperado de dificuldades financeiras será reduzida, levando-o a aumentar o endividamento com o intuito de aproveitar o benefício fiscal resultante (ou qualquer outro tipo de benefício das dívidas). Considerando apenas o viés do otimismo, Fairchild (Op. cit.) chega à mesma conclusão em modelos que também incluem assimetria informacional e conflitos de interesse.

A associação positiva entre o grau de otimismo e de excesso de confiança do gestor e o nível geral de endividamento da empresa é, de fato, a única predição não ambígua no conjunto das teorias enfocadas. Portanto, justifica-se uma atenção particular à sua verificação empírica.

\section{Método da Pesquisa}

\subsection{Definição operacional de otimismo/excesso de confiança - discussão teó- rica}

Embora alguns modelos tratem do otimismo e do excesso de confiança separadamente para fins analíticos, as pesquisas psicológicas e comportamentais revelam que, na realidade, estes vieses são estreitamente relacionados entre si e aparecem em conjunto (Taylor e Brown, op. cit.). Em outras palavras, um indivíduo otimista tenderá a ser excessivamente confiante e vice-versa. Logo, as definições operacionais para otimismo e excesso de confiança normalmente não precisarão distinguir 
entre os dois conceitos. Ademais, as predições comportamentais testadas nesta pesquisa são as mesmas independentemente de qual dos vieses é enfocado.

Naturalmente, os vieses cognitivos de interesse não são diretamente observáveis. Logo, é preciso identificar variáveis substitutas plausivelmente correlacionadas com os mesmos. No presente estudo, propõe-se uma definição operacional para os referidos vieses inédita na literatura de finanças e baseada em teorias e evidências empíricas robustas, segundo as quais os gestores que são também empreendedores (isto é, gerenciam seu próprio negócio) apresentam comportamentos mais otimistas e excessivamente confiantes do que a média da população e do que seus pares "não-empreendedores". 3

Em primeiro lugar, há indícios de que pessoas que dirigem o seu próprio negócio são mais propensas a exibir o viés da ilusão do controle. Em particular, Evans e Leighton (1989) documentam, numa amostra em painel com quase 4.000 homens norte-americanos, que empreendedores acreditam com maior intensidade, em comparação com os demais componentes da amostra, que sua performance depende largamente dos seus próprios atos. Simetricamente, os autores registram que indivíduos que exibem esta crença apresentam maior probabilidade de ingresso em atividades empreendedoras. Por sua vez, o estudo experimental de McKenna (1993), entre outros, sugere que o otimismo exagerado associa-se fortemente com a ilusão do controle.

Um trabalho seminal comparando diretamente características psicológicas de empreendedores com as de gestores não-empreendedores de grandes empresas norte-americanas foi apresentado por Busenitz e Barney (1997). Em sua cuidadosa investigação empírica, os autores contaram com uma amostra de 124 empreendedores, isto é, indivíduos que abriram e administravam o seu próprio negócio, e 95 gestores profissionais de grandes empresas, ocupando diversas posições de responsabilidade média ou elevada. Dois vieses cognitivos, dentre eles o da confiança excessiva, foram mensurados por meio da aplicação de questionários respondidos pelos componentes da amostra. O questionário relativo ao viés do excesso de confiança é similar ao proposto por Fischhoff et alii (Op. cit.) e captura erros sistemáticos de calibração de probabilidades, conforme discutido anteriormente. Mesmo isolando características psicológicas, como o grau de propensão ao risco; e pessoal-demográficas, a exemplo da idade e formação do indivíduo, dentre outras, Busenitz e Barney (Op. cit.) verificam estatisticamente que os gestores empreendedores revelam-se substancialmente mais excessivamente confiantes do que os

${ }^{3}$ Uma alternativa a esta abordagem seria a montagem de situações experimentais ou a aplicação de questionários a serem respondidos pelos gestores das empresas que compõem a amostra selecionada. Estes enfoques apresentam importantes dificuldades, porém. Em primeiro lugar, impõe-se a dificuldade operacional de se conseguir entrevistas individuais com ou respostas de questionários de um número significativo de executivos chefes, mais especificamente Diretores Presidentes e Presidentes do Conselho de Administração das empresas. Ademais, queremos identificar a confiança excessiva ou o otimismo dos gestores em situações reais de tomada de decisões corporativas e não simplesmente como um traço genérico de personalidade. Neste caso, o uso de questionários, os quais descrevem situações inevitavelmente artificiais, pode não ser uma estratégia adequada aos propósitos da pesquisa. 
gestores profissionais. Na mesma linha, Baron (2000a) encontra evidências compatíveis com a suposição de que os empreendedores (ou indivíduos que desejam se tornar empreendedores) são especialmente otimistas e excessivamente confiantes, estudando uma amostra dividida entre empreendedores estabelecidos, empreendedores em potencial e não-empreendedores. Outras evidências são oferecidas por Baron (1998) e alguns trabalhos relacionados são comentados pelo mesmo autor em Baron (2000b).

Arabsheibani et alii (2000) utilizam respostas de questionários de uma grande amostra incluindo empreendedores e não-empreendedores ingleses obtida do British Household Panel Study, abrangendo os anos de 1990 a 1996. Os dados permitem a captura ao longo deste período dos erros de previsão dos indivíduos quanto às suas perspectivas de renda (ou condição financeira) para o ano subseqüente. Os autores encontram evidências de otimismo excessivo em todas as subamostras, mas este viés é claramente e substancialmente mais pronunciado entre os empreendedores (self-employed), mesmo controlando possíveis fontes de heterogeneidade entre estes grupos, a exemplo de gênero, estado civil e nível educacional.

Em outro estudo empírico, Palich e Bagby (1995) mostram que os empreendedores geralmente percebem um maior potencial de ganho em situações que envolvem elevada incerteza do que os não-empreendedores. Eles revelam também um maior enviesamento na percepção dos riscos envolvidos. Pinfold (2001), por sua vez, encontra evidências de que os empreendedores neozelandeses normalmente superestimam as chances de sucesso dos seus projetos. Utilizando uma amostra de quase 3.000 empreendedores norte-americanos, Cooper et alii (1988) oferecem evidências similares. Zacharakis e Shepherd (2001) enfocam financiadores profissionais de novos empreendimentos (venture capitalists) e argumentam que seu processo decisório se assemelha ao dos empreendedores, baseando-se fortemente em heurísticas de decisão. Os autores reportam que $96 \%$ dos 51 componentes da sua amostra de venture capitalists exibem excesso de confiança em seus julgamentos quanto ao potencial de sucesso ou fracasso de novos negócios por eles avaliados.

Diferentes análises teóricas produzem predições consistentes com as evidências empíricas relacionadas acima. No modelo de De Meza e Southey (1996), por exemplo, os autores concluem que o valor esperado da entrada em atividades empreendedoras deve ser negativo no equilíbrio da economia, quando avaliado sob probabilidades de sucesso corretas (Ibid., p. 383-4). Como conseqüência, neste estágio todos os novos empreendedores serão necessariamente pessoas que superestimam a probabilidade de sucesso de novos negócios (otimistas), embora alguns indivíduos enviesados não escolham este tipo de ocupação em razão, por exemplo, da insuficiência de recursos próprios. Uma conclusão similar é oferecida pelo modelo mais simplificado de Landier e Thesmar (2004). Na mesma linha, o estudo experimental de Camerer e Lovallo (1999) sugere que o excesso de confiança em suas próprias habilidades pode ser responsável pela decisão de muitas pessoas, 
freqüentemente precipitada, de entrada em atividades empreendedoras. Bernardo e Welch (2001), por sua vez, oferecem um modelo evolutivo no qual justificam a sobrevivência de agentes com estes tipos de enviesamento cognitivo (os quais os autores definem como "empreendedores") no ambiente econômico.

Os argumentos e evidências arrolados nesta seção sugerem que os gestores que também são empreendedores (isto é, fundaram ou gerenciam os seus próprios negócios) apresentam os vieses do otimismo e do excesso de confiança mais freqüentemente ou de forma mais pronunciada do que os demais. Assumindo-se que este é o caso, justifica-se o uso da separação das empresas entre aquelas geridas por "empreendedores" e as geridas por "não-empreendedores" (ou "profissionais") como estratégia principal de identificação empírica da presença dos referidos vieses. Não obstante, para verificar a robustez dos resultados, definições operacionais alternativas, baseadas no padrão de propriedade de ações da própria empresa por parte do seu gestor, serão também utilizadas, como justificado abaixo.

Do ponto de vista da teoria tradicional de Finanças, num mercado eficiente os benefícios da correta diversificação dos investimentos individuais não deveriam ser desprezados por um agente racional. Em contraste, observa-se que muitos investidores detêm carteiras flagrantemente subdiversificadas (French e Poterba, 1991, Huberman, 2001). Em particular, muitos tendem a aplicar em excesso em ações das empresas nas quais trabalham (Benartzi, 2001). Considerando-se que os gestores das empresas já são naturalmente expostos aos riscos próprios do negócio em razão do vínculo entre suas carreiras e os destinos do empreendimento (Treynor e Black, 1976, Gervais et alii, op. cit.), parece ainda mais anômalo que estes indivíduos mantenham uma carteira subdiversificada por aplicarem excessivamente em ações de sua própria empresa. Conquanto explicações alternativas possam dar conta deste comportamento, é plausível que ele seja motivado, pelo menos em parte, por vieses cognitivos.

Especificamente, muitos gestores experimentam a ilusão do controle (March e Shapira, op. cit.), superestimando sua capacidade de influenciar a performance do negócio e, ao mesmo tempo, confiam excessivamente em suas próprias habilidades gerenciais, o que os torna injustificadamente otimistas quanto às perspectivas do empreendimento. Pessoas com este perfil tendem a minimizar os riscos e a superestimar o potencial de retorno das ações da sua empresa. Tal enviesamento, por sua vez, poderia explicar o elevado e aparentemente subótimo investimento pessoal de muitos gestores em ações da própria empresa.

Alternativamente, esta subdiversificação dos gestores poderia, por vezes, ser motivada por informações privilegiadas em seu poder acerca de perspectivas do negócio ainda não incorporadas ao preço da ação. Neste caso, porém, seria de se esperar que o gestor se desfizesse do seu excesso de investimento na medida em que suas informações se tornam públicas e são incorporadas ao valor de mercado do título. Em contraste, observa-se, em muitos casos, que os gestores mantêm um investimento constantemente elevado em ações da própria empresa ao longo de vários anos. Ademais, a aposta em ganhos decorrentes de informações privi- 
legiadas pode ser bastante arriscada. Não se pode garantir, por exemplo, que o mercado reagirá favoravelmente ao anúncio oficial de uma fusão ou aquisição que pareça vantajosa do ponto de vista do gestor. Logo, apostar todas as fichas (ou muitas fichas) nestas informações pode, novamente, ser um indicativo de excesso de confiança e otimismo, especialmente se os retornos obtidos com a ação não se revelarem compensadores ex post.

A posse de muitas ações da própria empresa poderia também ser justificada pelos benefícios privados do controle, nos casos em que o gestor é o controlador ou pertence ao grupo de controle da companhia. Esta questão é extensamente explorada na literatura sobre governança corporativa e sobre conflitos de interesse entre administradores e investidores externos. Não obstante, as principais pesquisas nestas áreas não explicam por que muitos gestores controladores detêm um número de ações da própria empresa bastante superior ao necessário para garantir-lhes o direito de controle do negócio.

Por fim, é possível argumentar que o gestor poderia racionalmente adquirir ações da própria empresa com o intuito de transmitir sinais ao mercado acerca das (supostamente) boas perspectivas daquele empreendimento (Malmendier e Tate, 2002, 2003). Todavia, assim como no caso das informações privilegiadas, seria de se esperar que a iniciativa de sinalização fosse episódica e não se refletisse em níveis constantemente elevados de posse destas ações. Ademais, é provável que a recompra de ações pela empresa seja uma forma menos custosa de atingir os objetivos da sinalização do que a compra pela pessoa física do gestor.

Em suma, é plausível interpretar a subdiversificação dos gestores causada pelo excesso de ações da própria empresa em sua carteira pessoal como um reflexo de seu otimismo e excesso de confiança, pelo menos em certos casos. Especificamente, poder-se-ia definir operacionalmente como enviesados os gestores que, dentro da amostra, mantêm sistematicamente por vários anos as maiores proporções de ações da própria empresa em sua carteira pessoal ou os maiores valores monetários (quantidade de ações multiplicada pela cotação das mesmas).

\subsection{Determinantes da estrutura de capital e variáveis de controle}

Esta pesquisa se insere na vasta literatura empírica sobre os “determinantes" da estrutura de capital, entendidos como os fatores efetivamente relevantes para explicar os padrões de financiamento observados das empresas. A proficuidade desta linha de pesquisas resulta da diversidade de argumentos teóricos disponíveis, os quais foram revisados por, dentre outros, Harris e Raviv (1991) e, mais recentemente, por Myers (2003). São exemplos desta literatura os trabalhos de Titman e Wessels (1988), Rajan e Zingales (1995), Fama e French (2002) e Frank e Goyal (2004). No Brasil, também diversos trabalhos estão disponíveis, dentre eles os oferecidos por Gomes e Leal (2000), Perobelli e Famá (2002), Klotzle e Biagini (2004) e Brito e Lima (2005). Leal e Saito (2003) oferecem uma revisão das pesquisas empíricas com dados brasileiros.

Os modelos empíricos utilizados neste trabalho e descritos abaixo incorporam 
os determinantes potenciais do endividamento mais freqüentemente utilizados nas pesquisas anteriores e contribuem para a referida literatura acrescentando as proxies para o otimismo e excesso de confiança dos gestores. Portanto, embora o foco do trabalho seja o teste da hipótese comportamental discutida acima, acessoriamente os candidatos a determinantes da estrutura de capital tradicionais serão também testados, ao mesmo tempo em que desempenham o papel fundamental de variáveis de controle das regressões.

Dentre os potenciais determinantes das decisões de financiamento sugeridos pela literatura destacam-se proxies para: a quantidade de oportunidades de investimento rentável disponíveis para a empresa; seu grau de lucratividade; o grau de tangibilidade de seus ativos; seu tamanho; a volatilidade do negócio; seu acesso a benefícios fiscais extra-dívida (com base no volume de ativos depreciáveis, por exemplo); o grau de singularidade de seus produtos e serviços; e sua taxa de pagamento de dividendos. Estudos anteriores sugerem ainda outros fatores, não obstante, que podem influenciar significativamente a decisão de financiamento da empresa. Incluem-se aí fatores macroeconômicos como inflação (Frank e Goyal, 2004) e variação da taxa de câmbio (Klotzle e Biagini, op. cit.) e relacionados com a estrutura de propriedade da empresa (Procianoy e Schnorrenberger, 2004) ou com outras características de sua governança corporativa (Brito e Lima, op. cit.). Todos estes elementos são incorporados, direta ou indiretamente, aos modelos empíricos descritos abaixo, na maior parte dos casos por meio de proxies empregadas em pesquisas anteriores (vide Tabela A.1 e Seção 3.6.3).

\subsection{Dados}

A base de dados do trabalho é composta por uma amostra de 153 empresas não financeiras com ações negociadas na Bovespa, Bolsa de Valores de São Paulo. Os dados coletados compreendem o período de 1998 a 2003, embora nem todas as empresas tenham dados disponíveis em todos os anos para todas as variáveis, caracterizando a amostra como um painel não balanceado.

Uma vez que são utilizadas cotações de preço das ações para o cálculo do valor de mercado das empresas, impôs-se um critério de liquidez para a seleção da amostra. Utilizando o índice de liquidez anual das ações disponibilizado pelo sistema de informações Economática, foram selecionadas apenas as (153) empresas com dados suficientes que apresentaram índice superior a 0,001\% do índice da empresa mais líquida em pelo menos $50 \%$ dos anos abrangidos pela pesquisa. As empresas selecionadas representam cerca de $40 \%$ do total de empresas listadas na Bovespa no período da amostragem e estão distribuídas entre 17 setores de atividade diferentes (dentre 20 setores possíveis, segundo a classificação da Economática).

As informações pessoais sobre os gestores (Diretor Presidente e do Presidente do Conselho de Administração) foram coletadas através do sistema DIVEXT, Divulgação Externa ITR/DFP/IAN da CVM, Comissão de Valores Mobiliários. Mais especificamente, estes dados, disponíveis a partir de 1998, foram coletados nos formulários IAN, Informações Anuais, preenchidos obrigatoria- 
mente pelas empresas de capital aberto autorizadas a negociar suas ações publicamente. Do IAN constam diversos tipos de informação sobre a empresa e sobre os seus diretores e conselheiros. Boa parte dos dados pessoais foi extraída, em particular, de um quadro do IAN denominado Experiência Profissional e Formação Acadêmica de Cada Conselheiro e Diretor. Este documento contém uma pequena biografia dos gestores, a partir da qual se pode inferir, por exemplo, se ele é um profissional de carreira ou também um empreendedor, fundador da empresa ou herdeiro do negócio. Nos casos em que as informações do IAN são insuficientes, recorreu-se a uma pesquisa complementar na Internet, em particular nos sites das próprias empresas e na imprensa em geral.

Foram coletados dados pessoais do Diretor Presidente e do Presidente do Conselho de Administração de cada empresa em cada um dos seis anos pesquisados. Estas informações se referem a: nome do gestor, ano de nascimento, ano em passou a ocupar o cargo (de Diretor Presidente ou Presidente do Conselho de Administração), gênero (homem ou mulher), formação (enquadrada como financeira, geral ou técnica), status (se é ou não fundador da empresa, herdeiro ou controlador) e quantidade de ações preferenciais e ordinárias da empresa de sua propriedade. Diversos dados secundários das empresas da amostra foram coletados utilizando-se o sistema Economática, assim como o sistema DIVEXT da CVM.

\subsection{Métodos empíricos e discussão metodológica}

A maior parte das teorias sobre estrutura de capital sugere que as empresas estabelecem um nível de alavancagem "meta" ou "ótimo" como função de um ou mais determinantes de suas decisões de financiamento. Supondo que os candidatos a determinantes da estrutura de capital disponíveis nesta pesquisa sejam agrupados no vetor $\mathbf{x}$, o modelo empírico pode ser formulado como

$$
A L A V_{i t}^{*}=\boldsymbol{\beta}^{T} \mathbf{x}_{i t}+u_{i}+\eta_{1 i t}
$$

Na equação acima, o ano é representado por $t(t=1,2, \ldots, 6$ anos), a empresa por $i\left(i=1,2, \ldots, 153\right.$ empresas) e $A L A V_{i t}^{*}$ é a medida de endividamento relativo ("alavancagem") meta ou ótima da empresa $i$ no ano $t$. O termo $u_{i}$ captura eventuais características não-observadas e invariantes no tempo das empresas que influenciam $A L A V_{i t}^{*}$ enquanto que o componente de erro $\eta_{1 i t}$ agrupa possíveis variáveis ausentes do modelo e/ou erros de mensuração dos regressores. $\beta^{T}$ corresponde ao vetor de parâmetros $\beta$, transposto.

Se não existissem custos de transação e ajustamento as empresas responderiam imediatamente a qualquer variação de sua meta de endividamento migrando para um nível maior ou menor de alavancagem. Neste caso, representando por $A L A V_{i t}$ a alavancagem efetivamente observada da empresa $i$ no ano $t$, teríamos sempre $A L A V_{i t}=A L A V_{i t}^{*}$ (a menos de algum choque aleatório que deslocasse contemporaneamente $A L A V_{i t}$ ). Entretanto, custos de transação significativos e outras 
fricções podem impedir que a alavancagem ótima seja plenamente alcançada. Este processo pode ser representado por um modelo de ajustamento parcial do tipo

$$
A L A V_{i t}-A L A V_{i t-1}=\lambda\left(A L A V_{i t}^{*}-A L A V_{i t-1}\right)+\eta_{2 i t}
$$

sendo $\eta_{2 i t}$ um choque aleatório com esperança zero que pode influenciar a variação da alavancagem de um ano para outro e $\lambda$ o coeficiente de ajustamento parcial, com $0<\lambda<1$. Se $\lambda$ fosse igual a 1 esperaríamos sempre que a alavancagem observada da empresa correspondesse à sua meta. O parâmetro $\lambda$ pode ser visto também como um coeficiente de velocidade de ajustamento, de forma que valores mais próximos de 1 sugerem um ritmo mais rápido de ajustamento em direção à meta. Substituindo em e rearranjando os termos obtêm-se

$$
A L A V_{i t}=(1-\lambda) A L A V_{i t-1}+\lambda \beta^{T} \mathbf{x}_{i t}+\lambda u_{i}+\lambda \eta_{1 i t}+\eta_{2 i t}
$$

A expressão acima pode ser simplificada na forma do modelo dinâmico abaixo

$$
A L A V_{i t}=\alpha A L A V_{i t-1}+\boldsymbol{\theta}^{T} \mathbf{x}_{i t}+c_{i}+\eta_{i t}
$$

sendo $\alpha \equiv(1-\lambda), \eta_{i t} \equiv \lambda \eta_{1 i t}+\eta_{2 i t}, c_{i} \equiv \lambda u_{i}$ e $\theta \equiv \beta$. A heterogeneidade não-observada e invariante no tempo é agora representada por $c_{i}$ e $\eta_{i t}$ representa o componente de erro do modelo, com $\mathbb{E}\left[\eta_{i t}\right]=\mathbb{E}\left[c_{i}\right]=0$ (E्E. $]$ é o operador de esperança). Logo, se um processo de ajustamento parcial em direção a uma estrutura de capital meta descrever adequadamente o comportamento das empresas, é preciso acrescentar ao conjunto de regressores do modelo uma defasagem da variável de resposta. A omissão de $A L A V_{i t-1}$ tornará inconsistente a estimação dos parâmetros contidos no vetor $\theta$, neste caso, na medida em que exista correlação entre esta variável e um ou mais componentes de $\mathbf{x}_{i t}$. Diferentes versões do argumento acima foram utilizadas (com propósitos distintos) em trabalhos recentes sobre estrutura de financiamentos, a exemplo de Fama e French (Op. cit.), Frank e Goyal (2003) e Gaud (2005). No Brasil, Martin et alii (2005) utilizam uma formulação similar.

Outros argumentos também poderiam justificar a preferência por formulações como a mostrada em em comparação com as mais tradicionalmente encontradas na literatura da área. Independentemente da existência de uma estrutura de capital meta perseguida pelas empresas, é comum observar-se algum comportamento de regressão à média em variáveis corporativas, induzindo uma correlação negativa entre os valores atuais destas variáveis e variações subseqüentes das mesmas. Um modelo dinâmico como o formulado acima poderia capturar adequadamente um comportamento desta natureza. Argumenta-se, ainda, que defasagens da variável dependente podem isolar diversas influências causadas por variáveis potencialmente omitidas do modelo original. Vide, por exemplo, Finkel (1995, p. 7-11). 
$\mathrm{Na}$ equação (4), o vetor de parâmetros $\theta$ contém os coeficientes a serem estimados (além de $\alpha$ ) e pode incluir uma constante geral. Já no vetor $\mathbf{x}$ devem figurar todas as variáveis de controle e, em especial, a proxy para o grau de excesso de confiança/otimismo do gestor, representada por $C E_{i t}$ (como abreviação para 'confiança excessiva/otimismo'). Por sua vez, dependendo do método de estimação empregado, o componente $c_{i}$ pode isolar todas as características nãoobservadas e invariantes no tempo da empresa $i$, mitigando problemas decorrentes de variáveis omitidas do modelo. Embora uma formulação dinâmica seja provavelmente mais adequada, também versões estáticas dos modelos (isto é, excluindo $A L A V_{i t-1}$ do conjunto dos regressores) serão estimadas para verificar a estabilidade dos resultados e torná-los mais comparáveis com os obtidos pela maior parte das pesquisas anteriores sobre os determinantes da estrutura de capital.

A estimação de modelos empíricos baseados em ou em suas versões estáticas deveria levar em conta explicitamente as fontes de endogeneidade potencialmente mais relevantes para o problema em questão, capazes de prejudicar a correta identificação dos relacionamentos entre as variáveis. ${ }^{4}$ A literatura teórica e empírica de finanças corporativas sugere, em particular, a existência de uma relação de causalidade de mão-dupla (ou de determinação simultânea) entre a alavancagem das empresas e certos indicadores corporativos. Por exemplo, diferentes argumentos teóricos levam a crer que o valor de mercado, como proxy para as oportunidades futuras de investimento disponíveis, pode influenciar contemporaneamente a política de financiamento das empresas (Fama e French, op. cit.). Ao mesmo tempo, outras linhas de argumentação sugerem que a alavancagem pode exercer influência sobre a performance da organização, por exemplo, por meio da redução do seu caixa disponível, o qual poderia ser utilizado ineficientemente por gestores autointeressados, contribuindo, em parte, para a determinação do valor de mercado da mesma (Stulz, 1990, McConnell e Servaes, 1995). Pesquisas recentes também sugerem que a estrutura de capital pode influenciar a política de distribuição de dividendos das empresas, ao mesmo tempo em que é por ela influenciada (Fama e French, op. cit.). Raciocínios análogos podem ser aplicados a algumas outras variáveis, tornando ambíguo, em muitos casos, o sentido das relações de causalidade esperadas. Ignorar a possível determinação simultânea da alavancagem e de alguns dos regressores contidos no vetor $\mathbf{x}$ pode, por sua vez, tornar inconsistente o estimador dos parâmetros do modelo.

Para lidar com a questão da determinação simultânea e com outras fontes de endogeneidade, utiliza-se nesta pesquisa um procedimento de estimação robusto baseado no Método dos Momentos Generalizado (Generalized Method of Moments, GMM), proposto por Blundell e Bond (1998) e conhecido na literatura econométrica como GMM Sistêmico (GMM-Sis). O GMM-Sis é apropriado

\footnotetext{
${ }^{4}$ Entendendo-se por endogeneidade a correlação entre um ou mais regressores e o termo de erro do modelo. Este problema pode ser motivado, principalmente, por variáveis omitidas, pela determinação simultânea de regressores e variável de resposta ou por erros de mensuração das variáveis explicativas e resulta na inconsistência dos estimadores que ignoram a sua existência.
} 
para modelos dinâmicos com heterogeneidade não-observada como o descrito pela equação (4) e baseia-se normalmente no uso de defasagens dos regressores suspeitos de endogeneidade como variáveis instrumentais. As condições que asseguram a validade desta estratégia de estimação são discutidas por Blundell e Bond (Ibid.) e a plausibilidade estatística das mesmas pode ser testada formalmente com base nos dados disponíveis.

Blundell et alii (2000) utilizam dados simulados e também dados reais de empresas com características similares aos disponíveis em pesquisas na área de finanças corporativas para comparar o desempenho de diferentes métodos de estimação aplicados a modelos especificados analogamente ao mostrado em . Seus resultados apontam claramente para a superioridade do GMM-Sis em comparação com estimadores mais tradicionais ${ }^{5}$ quando existe significativa heterogeneidade não-observada e algum grau de endogeneidade dos regressores (motivada, por exemplo, por erros de mensuração ou por sua determinação simultânea com a variável dependente). Blundell et alii (Ibid.) mostram, em particular, um enviesamento substancial do estimador mais comumente aplicado a modelos dinâmicos com dados em painel desenvolvido por Arellano e Bond (1991) e conhecido como GMM em Diferenças (GMM-Dif). ${ }^{6}$ O GMM-Dif foi utilizado em estudos recentes sobre os determinantes da estrutura de capital, a exemplo dos oferecidos por Gaud et alii (Op. cit.) e, no Brasil, Martin et alii (Op. cit.). Por sua vez, o estimador sistêmico de Blundell e Bond (Op. cit.) ainda não foi empregado em pesquisas deste tipo, até onde sabemos.

Conquanto o método GMM-Sis seja mais robusto, outras estratégias de estimação, discutidas na Seção 4.3 abaixo, serão utilizadas, com o intuito de verificar a estabilidade dos resultados.

\subsection{Alavancagem contábil e de mercado}

As teorias de estrutura de capital não oferecem orientação imediata sobre as medidas precisas de alavancagem que deveriam ser utilizadas em estudos empíricos. Em particular, pode ser mais apropriado utilizar medidas "contábeis" de alavancagem em alguns casos e "de mercado" em outros, embora esta escolha seja, por vezes, pouco clara.

Considere a seguinte possibilidade discutida por Titman e Wessels (Op. cit., p. 7-8). Se as decisões de financiamento forem irrelevantes para as empresas os gestores poderiam, por exemplo, definir aleatoriamente um grau de alavancagem meta. Se esta meta for estabelecida em termos contábeis (por exemplo, pela

\footnotetext{
${ }^{5}$ Incluindo os conhecidos estimadores de Efeitos Fixos (EF) e Mínimos Quadrados Ordinário (MQO).

${ }^{6} \mathrm{O}$ enviesamento em amostras finitas do procedimento de Arellano e Bond (Ibid.) decorre da característica de elevada persistência temporal (comportamento auto-regressivo) das variáveis explicativas, atributo comum a diversos indicadores corporativos, a exemplo da alavancagem e de outras medidas baseadas em dados contábeis. O estudo de Blundell et alii (Op. cit.) revela, ademais que, nestas circunstâncias, o método GMM em Diferenças é relativamente ineficiente em comparação com o GMM Sistêmico.
} 
razão entre o endividamento total e o ativo contábil da empresa) nenhum regressor seria significante para explicar o comportamento (aleatório, por definição) da alavancagem contábil. Todavia, alguns regressores, correlacionados com o valor de mercado das empresas, poderiam influenciar significativamente sua razão endividamento/valor de mercado do ativo, induzindo uma correlação espúria entre as variáveis. Similarmente, outras correlações espúrias poderiam surgir se a meta aleatória fosse estabelecida pelos gestores considerando a alavancagem de mercado ao invés da contábil. Felizmente, como argumentam os autores, medidas de alavancagem contábeis e de mercado induzem, neste contexto, correlações espúrias em direções opostas. Logo, o uso alternado de ambas as definições operacionais ajuda a evitar que as conclusões sejam influenciadas por eventuais efeitos indesejáveis. Por outro lado, Fama e French (Op. cit., p. 8-9) argumentam que algumas predições teóricas implicam um claro relacionamento entre certos indicadores e a alavancagem contábil, mas não necessariamente entre os mesmos indicadores e a alavancagem de mercado (ou vice-versa), embora outras predições sugiram exatamente o mesmo relacionamento independentemente da medida de endividamento relativo. Novamente, esta argumentação sugere o uso tanto de medidas contábeis quanto de mercado da alavancagem como forma de avaliar a consistência dos resultados.

\subsection{Definição operacional das variáveis}

\section{Excesso de confiança/otimismo}

A discussão teórica constante da Seção 3.1 acima e as evidências empíricas disponíveis sugerem como principal definição operacional para os construtos 'confiança excessiva' e 'otimismo' a classificação do gestor como empreendedor (no sentido específico de um indivíduo que gerencia o seu próprio negócio) ou não-empreendedor. Neste caso, a variável, denominada $C E_{i t}$, assume a forma binária, com $C E_{i t}=1$ se o gestor da $i$-ésima empresa no $t$-ésimo ano foi caracterizado como empreendedor (excessivamente confiante/otimista) e $C E_{i t}=0$ se o mesmo foi classificado como não-empreendedor ("racional" ou menos excessivamente confiante/otimista).

Em princípio, poder-se-ia definir como o "gestor relevante" da empresa apenas o seu Diretor Presidente. Todavia, esta provavelmente não é a estratégia mais adequada para a construção de $C E_{i t}$ em razão da ambigüidade verificada em muitas empresas brasileiras sobre quem é o verdadeiro decisor de última instância no que concerne às principais decisões corporativas. Embora o Diretor Presidente certamente seja o responsável pelas decisões mais imediatas, é provável que em certas empresas, especialmente de controle familiar, a organização se amolde mais ao perfil do seu Presidente do Conselho de Administração, freqüentemente o fundador e/ou controlador do negócio. A sua não consideração como um possível decisor relevante, neste caso, poderia conduzir a uma classificação incorreta do gestor. Naturalmente, nos casos em que ambos os cargos são ocupados pela mesma pessoa não há ambigüidade possível (isto ocorre em aproximadamente $40 \%$ das 
observações). De fato, quando se define o gestor relevante como o Diretor Presidente ou o Presidente do Conselho de Administração, em contraste com a definição mais restritiva que considera apenas o primeiro, as discrepâncias de classificação se restringem a uma parcela relativamente pequena da amostra (inferior a 10\% do total de observações).

Com base no exposto acima, define-se $C E_{i t}=1$ se o Diretor Presidente (DP) ou o Presidente do Conselho de Administração (PC) da empresa $i$ no ano $t$ é o fundador ou herdeiro do negócio e $C E_{i t}=0$ caso nenhum dos gestores se enquadre nestas categorias (caracterizando-os, portanto, como 'gestores profissionais'). Embora sejam menos justificáveis, definições operacionais similares, porém considerando como gestor apenas o DP ou apenas o PC das empresas são utilizadas nas análises de robustez dos resultados constantes da Seção 4.3 abaixo.

A classificação como empreendedor apenas do fundador da empresa não é a mais adequada para a amostra em questão porque pode induzir a erros de classificação, uma vez que virtualmente todos os herdeiros das empresas pesquisadas possuem clara atuação empreendedora, influenciando decisivamente os rumos dos seus negócios e por vezes fundando novos empreendimentos. ${ }^{7}$ Uma definição operacional capaz de mitigar este problema consideraria como empreendedores apenas os gestores fundadores das empresas, porém excluindo da amostra todos os herdeiros. Esta alternativa é explorada nas análises de robustez dos resultados constantes da Seção 4.3.

Um outro conjunto de definições operacionais para os vieses cognitivos de interesse explora sua provável conexão com a posse de ações da empresa por parte dos seus gestores. Uma das definições propostas, neste caso, considera que $C E_{i t}=1$ se o DP ou o PC da empresa $i$ no ano $t$ possui uma quantidade (percentual) de ações ordinárias da mesma superior a 50\% (o necessário para assegurar o controle do negócio) e $C E_{i t}=0$ caso contrário. Outras variantes possíveis, por exemplo considerando no lugar do percentual de ações o logaritmo da 'riqueza investida' dos gestores, obtida através da multiplicação do número de ações de sua propriedade por seu correspondente valor de mercado, são definidas na Seção 4.3.

\section{Alavancagem}

Quatro definições alternativas são utilizadas, considerando o endividamento total ou de longo prazo e o ativo contábil ou sua versão "a valor de mercado". Especificamente, figuram no numerador o endividamento financeiro total da empresa $\left(E_{i t}\right)$, incluindo empréstimos e financiamentos e debêntures de curto e longo prazo ou, alternativamente, seu endividamento financeiro de longo prazo $\left(E L P_{i t}\right)$. Já no denominador aparecem o ativo total contábil $\left(A_{i t}\right)$ ou sua versão "a valor de mercado", definida como $A_{i t}-P L_{i t}+V A_{i t}$, sendo $P L_{i t}$ o patrimônio líquido da empresa e $V A_{i t}$ o valor de mercado total de suas ações. Novamente, os subscritos $i$ e $t$ referem-se, respectivamente, a empresa e ano.

\footnotetext{
${ }^{7}$ Como ilustração pode-se citar o herdeiro Abílio Diniz, DP até o ano 2000 e posteriormente PC do Grupo Pão de Açúcar.
} 


\section{Demais variáveis}

As definições operacionais referentes às demais variáveis utilizadas na pesquisa são resumidas na Tabela A.1 (todas as tabelas estão localizadas no Apêndice).

Diferentes indicadores $\left(I P V P_{i t}, Q_{i t}, V A P L_{i t}, V M A T_{i t}, C R_{i t}\right.$ e $\left.d A_{i t}\right)$ procuram capturar o valor de mercado relativo e as diferenças de oportunidades de crescimento das empresas. Um outro conjunto de variáveis, relacionadas com a estrutura do Conselho de Administração, com a concentração acionária e natureza dos controladores e com a adesão da empresa a programas de ADR (American Depositary Receipts) ou aos níveis diferenciados de governança da Bovespa tentam capturar as diferenças nos seus padrões de governança corporativa e estrutura de propriedade. Analogamente, outras proxies são definidas para cada um dos candidatos a determinantes da estrutura de capital apresentados na Seção 3.2, inspiradas em definições utilizadas em trabalhos anteriores, a exemplo de Titman e Wessels (Op. cit.), Perobelli e Famá (Op. cit.), Gomes e Leal (Op. cit.) e Fama e French (Op. cit.)

Variáveis indicadoras de tempo (dummies de ano) são utilizadas para isolar os choques macroeconômicos e efeitos agregados em geral que influenciaram a alavancagem das empresas dentro da janela temporal analisada. Finalmente, variáveis binárias setoriais foram acrescidas a algumas regressões com o intuito de isolar as idiossincrasias dos diferentes setores de atividade não refletidas nos demais regressores.

\section{Discussão dos Resultados}

\subsection{Algumas estatísticas descritivas}

Uma inspeção preliminar da amostra disponível revela que a distribuição das empresas entre os diversos setores (de acordo com o sistema de classificação da Economática, que inclui 20 categorias) é relativamente homogênea, com maior representação dos setores de Energia Elétrica (13,73\% do total) e de Telecomunicações $(11,11 \%)$. As empresas de controle familiar estão mais representadas na amostra em comparação com outros tipos de acionista controlador, perfazendo, em média (ao longo do período analisado), cerca de $47 \%$ do total de empresas. Observa-se, ainda, que nenhuma das empresas da amostra é controlada por bancos e que as proporções por tipo de acionista controlador mantiveram-se aproximadamente constantes entre os anos de 1998 e 2003. Estas informações constam das tabelas A.2 e A.3.

As estatísticas de média, desvio padrão, mediana, primeiro e terceiro quartis da maior parte das variáveis utilizadas na pesquisa são mostradas na Tabela A.4. Observa-se, por exemplo, que o endividamento das empresas como proporção do seu ativo é relativamente baixo, em média, e que seu padrão não difere muito independentemente do uso de versões contábeis ou a valor de mercado do ativo. Embora esta informação não esteja na tabela, os dados revelam também a ausência 
de qualquer tendência clara de crescimento ou decrescimento dos índices de alavancagem médios no tempo. Comparando apenas os anos de 1998 e 2003, as medidas contábeis de alavancagem mostram variação positiva de cerca de $12 \%$ ao passo que as medidas de mercado apresentaram variação negativa da ordem de 7\%. Quanto à estrutura de propriedade, verifica-se na Tabela A.4 uma acentuada concentração dos direitos de voto nas mãos dos acionistas controladores (74,2\%, em média) associada a uma substancialmente menor concentração da propriedade total (50,8\%, em média). Ademais, o número médio de membros do Conselho de Administração das empresas é aproximadamente igual a 7 e elas obtiveram um índice médio de lucratividade (LAJIRDA sobre ativo) igual a 0,149 ao longo do período analisado.

Além das informações contidas na Tabela A.4, destaca-se que aproximadamente $17 \%$ das empresas participam de programas de ADR e, em 2003, aproximadamente $21 \%$ delas havia aderido a algum dos Níveis Diferenciados de Governança Corporativa ou ao Novo Mercado da Bovespa. Em média (ao longo do período da amostra), em cerca de 38\% das empresas o Diretor Presidente acumulou o cargo de Presidente do Conselho de Administração. Quanto à caracterização dos gestores como "empreendedores" ou "não-empreendedores", observa-se que, em média, aproximadamente $43 \%$ das empresas foram classificadas como sendo geridas por indivíduos do primeiro grupo (empreendedores) de acordo com o critério descrito na Seção 3.6.1, terceiro parágrafo. Se apenas o Diretor Presidente for considerado como o gestor relevante, esta proporção cai para cerca de $37 \%$. Considerando-se apenas o Presidente do Conselho, a proporção é da ordem de $42 \%$, em média.

De forma geral, houve substancial rotatividade dos gestores no período amostral. Em apenas 49 empresas (32\% do total) não houve mudança de Diretor Presidente (DP) ou Presidente do Conselho de Administração (PC) ao longo do período. Em 79 empresas houve pelo menos uma mudança no cargo de PC e em 73 empresas houve pelo menos uma mudança no cargo de DP ao longo dos anos analisados. Ademais, houve mudanças dos principais cargos de gestão em 31 empresas geridas pelo fundador ou herdeiro do negócio. Nestas, em cerca de metade dos casos, houve a saída do fundador ou herdeiro para dar lugar a um gestor contratado.

As estatísticas descritivas das variáveis foram também computadas separadamente para duas subamostras, definidas como 'Grupo 1' (empresas geridas por empreendedores) e 'Grupo 2' (empresas geridas por não-empreendedores), utilizando o critério de classificação descrito na Seção 3.6.1, terceiro parágrafo. Estas comparações preliminares, não reportadas, revelam uma relativa homogeneidade de características entre os dois grupos. Observa-se, por exemplo, que as empresas do Grupo 1 são apenas discretamente mais alavancadas e menos lucrativas do que as demais e também que a concentração de ações ordinárias nas mãos do grupo controlador é virtualmente idêntica nos dois casos. Uma diferença mais pronunciada refere-se aos indicadores de tamanho da empresa, revelando que as 
enquadradas no Grupo 1 são menores, em média, do que as do Grupo 2. Registrase também que as componentes do Grupo 1 emitem menos ADRs e são menos propensas a distribuir dividendos. Testes convencionais de igualdade de médias mostram diferenças estatisticamente significantes nos níveis usuais para, em particular, os indicadores de alavancagem, lucratividade, tamanho e tangibilidade dos ativos. A exclusão da amostra das empresas controladas pelo Estado não altera materialmente estes resultados.

\subsection{Resultados principais}

Especificações dinâmicas similares à mostrada na equação (4) foram estimadas por meio do GMM Sistêmico (GMM-Sis) descrito por Blundell e Bond (Op. cit.) e duas delas são reportadas na Tabela A.5. Na segunda coluna da Tabela A.5 a variável dependente é uma medida de alavancagem representada pelo endividamento financeiro total da empresa dividido por seu ativo contábil. Na quarta coluna a alavancagem é representada pela razão entre o endividamento total e o ativo "a valor de mercado" da empresa (conforme definições constantes da Seção 3.6). As variáveis de controle e candidatos a determinantes da estrutura de capital incluídos nas regressões são descritos na nota explicativa da tabela, assim como os detalhes técnicos da implementação do estimador. Especificamente, assumese nestes modelos que as proxies para o valor de mercado $(I P V P)$, a lucratividade $(L A J I R D A)$, os benefícios fiscais extra-dívida $(B F E D)$, a volatilidade $(B F E D)$, a política de dividendos $(D I V)$ e a estrutura de propriedade $(C O N)$ das empresas são potencialmente endógenas (possivelmente em razão de sua determinação simultânea com a variável de resposta) e, por isso, seus valores defasados são utilizados como variáveis instrumentais. Por fim, as variáveis binárias indicativas do setor de atividade e do tipo de acionista controlador das componentes da amostra não apresentaram variação temporal e por isso foram excluídas das regressões.

A Tabela A.5 mostra coeficientes expressivos e significantes no nível de $1 \%$ para a variável de resposta defasada $\left(A L A V_{t-1}\right)$, confirmando a forte persistência temporal da alavancagem das empresas. Também a estimativa associada a um dos indicadores de padrões de governança corporativa $(A C U M)$ revela-se consistentemente significante e seu sinal sugere que empresas nas quais os cargos de Diretor Presidente e Presidente do Conselho de Administração são ocupados pelo mesmo indivíduo tendem a ser menos alavancadas. Ademais, dependendo da especificação do modelo, os coeficientes associados aos indicadores de lucratividade, tangibilidade, tamanho, volatilidade e concentração acionária do controlador mostram alguma significância, pelo menos no nível de 10\%. De interesse mais direto para esta pesquisa, não obstante, é o resultado reportado na segunda linha da tabela. Depois de isoladas características observáveis e não-observáveis das empresas, o coeficiente positivo da variável $C E$ revela-se positivo e estatisticamente significante no nos níveis de $5 \%$ ou $1 \%$, sugerindo que empresas geridas por "empreendedores" tendem a ser significativamente mais alavancadas do que as geridas 
por "profissionais", resultado compatível com as teorias comportamentais relacionadas na Seção 2.1.1.

Se, como discutido na Seção 3.4, um processo de ajustamento parcial caracterizar adequadamente o comportamento dinâmico da alavancagem, é possível recuperar os coeficientes (contidos no vetor $\boldsymbol{\beta}$ ) do modelo que descreve o comportamento da alavancagem meta das empresas, representado pela equação (1). A expressão mostra que $\boldsymbol{\theta}=\lambda \boldsymbol{\beta}$ e, portanto, $\boldsymbol{\beta}=\lambda^{-1} \boldsymbol{\theta}$. Conforme comentado na Seção $3.4, \lambda$ pode ser visto como um parâmetro que regula a velocidade do processo de ajustamento da alavancagem em direção a seu valor meta e, como definido anteriormente, $\lambda=1-\alpha$, sendo $\alpha$ o coeficiente da variável dependente defasada. Considerando as estimativas da Tabela A.5, o valor de $\hat{\lambda}$ é aproximadamente igual a $0,34(1-0,66)$ quando a variável de resposta é a alavancagem contábil e $0,2(1-0,80)$ quando variável de resposta é a alavancagem de mercado. ${ }^{8}$ As colunas 3 e 5 da tabela mostram os valores de $\hat{\beta}$ obtidos pela divisão por $\hat{\lambda}$ dos coeficientes estimados. Estas estimativas transformadas são, naturalmente, maiores (observando-se, não obstante, que algumas delas não são estatisticamente diferentes de zero, ainda que possuam valores absolutos elevados) e podem ser interpretadas como medidas do efeito de longo prazo da variável sobre a alavancagem meta ou de "equilíbrio", ao passo que as estimativas não transformadas capturariam impactos de curto prazo (para uma discussão genérica sobre esta interpretação, vide Finkel, op. cit., p. 11).

Para verificar a estabilidade dos resultados e torná-los mais comparáveis com os reportados em trabalhos anteriores, também foram estimadas regressões excluindo $A L A V_{t-1}$ do conjunto de variáveis explicativas. A Tabela A.6 traz as estimativas resultantes de duas especificações estáticas idênticas às reportadas na Tabela A.5 (com exceção da exclusão de $A L A V_{t-1}$ ). Os resultados são qualitativamente diferentes dos comentados acima para alguns dos regressores. Em particular, o coeficiente da variável binária $A D R$ revela-se, agora, significante no nível de 5\%, assim como o do indicador de tamanho da empresa. Para outros indicadores os resultados são qualitativamente similares, não obstante, como é o caso de $A C U M$. Destaca-se, em especial, que o coeficiente associado à medida de excesso de confiança/otimismo gerencial $(C E)$ permanece significante (no nível de $1 \%$ nas duas regressões) e positivo. As estimativas, variando entre, aproximadamente, 0,09 e 0,13, são maiores do que as reportadas na Tabela A.5, mas são bastante similares em magnitude aos coeficientes transformados pelo método descrito no parágrafo anterior (com valores situados entre 0,13 e 0,15 ). De forma geral, estes resultados mostram que a influência de $C E$ sobre o valor esperado da alavancagem parece relevante também do ponto de vista econômico, refletindo-se numa diferença substancial de grau de endividamento (ou de meta de endivida-

\footnotetext{
${ }^{8}$ No contexto do modelo de ajustamento parcial, estas estimativas sugerem que o processo de convergência da alavancagem das empresas brasileiras para seu valor meta é lento. Tal resultado é compatível com os reportados em pesquisas internacionais comparáveis (Fama e French, op. cit., Gaud et alii, op. cit.).
} 
mento) entre os grupos de empresas definidos por esta variável.

Em seguida à estimação dos modelos, diversas análises de diagnóstico foram implementadas com o intuito de testar a plausibilidade estatística dos pressupostos adotados. Dentre elas, computou-se testes de restrições de sobre-identificação de Hansen/Sargan, cuja hipótese nula é de especificação linear correta e ortogonalidade (não-correlação) entre o conjunto de instrumentos utilizado e os erros do modelo (vide, por exemplo, Arellano, 2003, p. 192-7). Como se observa nas tabelas A.5 e A.6, não é possível rejeitar nos níveis de significância usuais a hipótese nula, resultado que sugere que a suposição fundamental de não-correlação entre os instrumentos e o termo erro é plausível estatisticamente. O estudo de simulação de Bowsher (2002) mostra, todavia, que o poder destes testes (probabilidade de rejeitar uma hipótese nula falsa) tende a ser baixo quando o número de instrumentos é elevado e o tamanho da amostra é moderado, como é o caso nesta pesquisa. Para contornar tal deficiência, o autor sugere o cálculo dos mesmos testes utilizando subconjuntos apropriados no lugar do conjunto completo de instrumentos. Um procedimento similar ao utilizado por Bowsher (Ibid.) foi adotado, reduzindo significativamente o número de graus de liberdade dos testes. Os resultados foram qualitativamente semelhantes nestes casos, novamente sugerindo a não-rejeição da hipótese nula. A validade da estratégia de estimação adotada depende, em particular, de restrições sobre o padrão de autocorrelação dos erros dos modelos. Nas especificações reportadas nas tabelas A.5 e A.6, assume-se que os erros são não-autocorrelacionados, hipótese corroborada, em geral, pelos testes de autocorrelação propostos por Arellano e Bond (Op. cit.). ${ }^{9}$ Outros procedimentos de teste, não reportados, atestam a adequação da estratégia empírica adotada, especialmente no caso das especificações dinâmicas, como aquelas constantes da Tabela A.5.

No que tange à estimação dos erros-padrão dos coeficientes, as análises de diagnóstico sugerem o uso de estimadores robustos, em razão das suspeitas de heterocedasticidade dos erros dos modelos. É também possível, como argumentam Fama e French (Op. cit.), que as inferências em estudos sobre finanças corporativas sejam prejudicadas pela presença de correlação contemporânea dos erros causada por choques macroeconômicos ou efeitos de ciclos de negócios que afetam a variável de resposta. Para lidar simultaneamente com estas dificuldades, todas as regressões foram estimadas com dummies de ano, capazes de isolar os referidos choques e os erros-padrão dos coeficientes foram computados utilizando-se os dados agrupados por empresa, tornando-os assintoticamente robustos a formas arbitrárias de heterocedasticidade e autocorrelação dos termos de erro. Para uma discussão mais detalhada sobre a eficácia desta estratégia, vide Petersen (2005).

\footnotetext{
${ }^{9}$ Com exceção de uma regressão estática na qual a variável dependente é a alavancagem contábil. Variantes destas especificações, permitindo, por exemplo, que os erros exibam autocorrelação de primeira ordem, foram também estimadas e seus resultados são discutidos na próxima seção.
} 


\subsection{Análises de robustez dos resultados}

\section{Variáveis instrumentais e suposições dos modelos}

Com o intuito de verificar a estabilidade dos resultados e a confiabilidade das inferências, especialmente quanto à influência da proxy para o excesso de confiança/otimismo dos gestores sobre a alavancagem das empresas, diversas variantes da estratégia de investigação empírica foram empregadas. Em primeiro lugar, investigou-se a sensibilidade dos resultados a variações das hipóteses adotadas nas regressões reportadas nas tabelas A.5 e A.6. Especificamente, os modelos dinâmicos e estáticos comentados na seção anterior foram re-estimados assumindo-se que todos os regressores, com exceção das dummies de ano, são potencialmente endógenos (incluindo a variável de interesse $C E$ ). Também diferentes suposições sobre o padrão de autocorrelação dos erros foram adotadas. Como ilustração, os resultados obtidos com duas destas especificações alternativas são reportados na Tabela A.7, tratando todos os regressores como potencialmente endógenos e permitindo que os erros exibam autocorrelação de primeira ordem (suspeita induzida pelos testes de autocorrelação constantes da segunda coluna da Tabela A.6). Observa-se na Tabela A.7 que os resultados são qualitativamente similares aos comentados anteriormente. Em particular, os coeficientes estimados para $C E$ são maiores do que os reportados na Tabela A.6. O mesmo ocorre quando modelos dinâmicos são especificados similarmente (neste caso, não reportado, os coeficientes de $C E$ situam-se entre 0,050 e 0,057 e mantêm a significância no nível de 5\%).

\section{Definições operacionais alternativas de CE e demais regressores}

Em outras especificações, diferentes proxies para os construtos de interesse foram utilizadas. Por exemplo, empregou-se medidas de alavancagem de longo prazo no lugar das medidas de alavancagem total consideradas nas regressões reportadas até aqui. Também indicadores alternativos para alguns dos candidatos a determinantes da estrutura de capital foram considerados, quando disponíveis. Em alguns modelos, substituiu-se, por exemplo, os indicadores de oportunidades de crescimento $(C R$ por $d A$ ), lucratividade ( $L A J I R D A$ por $L O P A)$, tamanho (ln $R$ por $\ln A$ ) e política de dividendos ( $D I V$ por $P A Y O U T)$. As definições operacionais constam da Seção 3.6 e da Tabela A.1. De forma geral, o sinal positivo e a significância estatística da proxy para o excesso de confiança/otimismo gerencial se mantêm nestas regressões. Os resultados também mostram-se robustos a variações da forma funcional dos modelos (implementadas, por exemplo, através do acréscimo de termos quadráticos de alguns regressores nos casos em que há suspeita de não-linearidade no seu relacionamento com a variável de resposta).

Talvez mais importante, verificou-se a estabilidade dos resultados estimandose modelos com proxies alternativas para o grau de excesso de confiança/otimismo dos gestores. Na Tabela A.9 são reportados os coeficientes estimados associados a seis diferentes definições operacionais para estes vieses cognitivos, denomina- 
das $C E_{1}, C E_{2}, \ldots, C E_{6}$, cada uma delas utilizada em quatro modelos distintos (dois dinâmicos e dois estáticos e tendo como variável de resposta a alavancagem contábil ou de mercado). $C E_{1}$ é a mesma proxy utilizada anteriormente e figura na tabela para efeito de comparação. Sua definição consta da Seção 3.6.1, terceiro parágrafo: $C E_{1 i t}$ assume o valor 1 se o Diretor Presidente (DP) ou o Presidente do Conselho de Administração (PC) da empresa $i$ no ano $t$ é o fundador ou herdeiro do negócio e $C E_{1 i t}=0$ caso nenhum dos gestores se enquadre nestas categorias.

A definição de $C E_{2}$ desconsidera os herdeiros, de tal forma que $C E_{2 i t}=1$ se o DP ou o PC da empresa $i$ no ano $t$ é o fundador do negócio. Neste caso, para evitar erros de classificação (eventuais herdeiros com perfil empreendedor classificados como não-empreendedores) as empresas geridas por herdeiros são excluídas da amostra. Na prática, isto significa que $C E_{2 i t}=0$ quando o gestor é um "executivo profissional", não se enquadrando como fundador e nem como herdeiro.

A proxy denominada $C E_{3}$ define como o gestor relevante apenas o Diretor Presidente (DP) da empresa. Sua construção é análoga a de $C E_{1}$, tal que $C E_{3 i t}=1$ se o DP da empresa $i$ no ano $t$ é o fundador ou herdeiro do negócio e $C E_{3 i t}=0$ caso nem o DP e nem o PC se enquadre nestas categorias (os herdeiros ou fundadores que ocupam o cargo de PC são excluídos com o intuito de evitar erros de classificação). $C E_{4}$ é definida de forma similar, porém substituindo o DP pelo Presidente do Conselho de Administração como o gestor relevante.

As duas últimas definições operacionais exploram, com base nos argumentos da Seção 3.1, a provável conexão entre a subdiversificação da carteira pessoal dos gestores refletida, em particular, na posse de muitas ações da própria empresa, e seu grau de excesso de confiança/otimismo. Especificamente, a definição de $C E_{5}$ enfoca o excesso de ações com direito a voto nas mãos do principal gestor da empresa. Entende-se como "excesso", neste caso, a posse pelo gestor de mais do que $50 \%$ das ações ordinárias (logo, um número de ações maior do que o necessário para assegurar o controle do empreendimento). Em outros termos, $C E_{5 i t}=1$ se o DP ou o PC da empresa $i$ no ano $t$ possui mais do que $50 \%$ de suas ações ordinárias e $C E_{5 i t}=0$ caso contrário. Por fim, $C E_{6}$ considera o valor monetário investido pelo gestor em ações com ou sem direito a voto da própria empresa. Esta "riqueza investida" foi calculada por meio da multiplicação do percentual total de ações (ordinárias e preferenciais) em posse do gestor pelo valor de mercado das ações da empresa em cada ano $t$. Neste caso, $C E_{6 i t}=1$ se o DP ou o PC da empresa $i$ no ano $t$ possui uma 'riqueza investida' superior à mediana desta variável na amostra e $C E_{6 i t}=0$ se nenhum deles possui uma 'riqueza investida' superior à referida mediana. Um resumo esquemático das diversas definições operacionais aparece na Tabela A.8. 
As estimativas reportadas na Tabela A.9 foram obtidas com a aplicação do método GMM Sistêmico a modelos especificados de forma idêntica (com exceção da própria variável $C E$ ) aos reportados na Tabela A.6 (para os modelos estáticos) ou na Tabela A.5 (para as especificações dinâmicas). Desta forma, os resultados mostrados na Tabela A.9 são diretamente comparáveis com os comentados nas seções anteriores.

Pode-se observar na tabela que a magnitude dos coeficientes varia consideravelmente com as diferentes definições operacionais empregadas. Não obstante, em todos os casos seu sinal é positivo e na grande maioria das vezes a estimativa é significante estatisticamente nos níveis convencionais, apontando para as mesmas conclusões. De fato, em apenas um caso o coeficiente estimado é não-significante no nível de $10 \%$.

De forma geral, a proxy $C E_{2}$, a qual define como "cognitivamente enviesado" apenas o fundador da empresa, apresenta os resultados mais fortes no que concerne à magnitude das estimativas. Em termos de significância dos coeficientes, $C E_{6}$, relacionada com o montante investido pelo gestor em ações da própria empresa, revela os resultados mais pronunciados. Em ambos os casos, os resultados gerais são bastante similares aos obtidos com a proxy $C E_{1}$, utilizada nas regressões anteriores. No outro extremo, $C E_{5}$, vinculada à posse de ações ordinárias pelo gestor, apresentou, em todos os modelos, o coeficiente com menor magnitude e significância estatística. Ainda outras variantes destas definições operacionais foram construídas e testadas e os resultados obtidos são, de forma geral, coerentes com os comentados acima.

\section{Empresas familiares vs. não-familiares}

A grande maioria das empresas nas quais os gestores foram classificados como "enviesados", de acordo com as definições de descritas acima, são de controle familiar. Logo, poder-se-ia suspeitar que, mais do que capturar diferenças nos perfis psicológicos dos gestores, capturaria diferenças entre empresas familiares e nãofamiliares. A análise dos dados permite descartar esta última conjectura. Observase, em primeiro lugar, que, em muitas empresas de controle familiar, o gestor não é fundador ou herdeiro do negócio. Há casos, ainda, em que a família fundadora abriu mão do controle, mas o novo controlador manteve o empreendedor no comando da empresa. Não obstante, a forma mais direta de lidar com esta questão é a inclusão como variável de controle da regressão de uma dummy separando as empresas de natureza ou controle familiar das demais. A inclusão desta variável não afeta materialmente os resultados principais, mostrando que existe uma influência de sobre a alavancagem financeira independentemente da empresa ser ou não de controle familiar. 


\section{Variáveis latentes e Análise de Fatores Comuns}

Uma outra extensão da pesquisa fundamenta-se na modelagem explícita dos construtos de interesse como variáveis latentes (não-observadas) que influenciam os indicadores observados (proxies). Por exemplo, o faturamento da empresa e seu ativo total podem ser interpretados como indicadores que refletem o construto teórico 'tamanho' ou 'porte' da empresa. A variável latente 'estrutura do Conselho de Administração' pode estar refletida, por sua vez, em diferentes indicadores, tais como o número total de membros do conselho, a proporção de conselheiros independentes e o acúmulo dos cargos de Diretor Presidente (DP) e Presidente do Conselho de Administração (PC) pelo mesmo indivíduo. De particular interesse é a representação do construto 'confiança excessiva/otimismo do gestor' como uma variável latente refletida, supõe-se, nas diferentes proxies mencionadas acima. Estas definições operacionais alternativas para um mesmo construto foram, então, combinadas por meio de uma Análise Fatorial exploratória. Este procedimento, análogo ao utilizado por Perobelli e Famá (Op. cit.), produziu escores fatoriais, interpretados como estimativas das variáveis latentes. Os escores fatoriais foram, em seguida, utilizados como regressores em modelos similares aos comentados anteriormente e estimados pelo método GMM Sistêmico. De forma geral, os coeficientes estimados para os escores fatoriais são menores em valor absoluto (estas regressões não são reportadas por economia de espaço). Em compensação, as estimativas são mais precisas, apresentando, em muitos casos, erros-padrão substancialmente inferiores aos obtidos previamente. No cômputo geral, as conclusões quanto ao sentido e significância dos relacionamentos entre as principais variáveis são mantidas. O uso de estimativas das variáveis latentes em lugar de indicadores individuais nas regressões pode ser útil para mitigar problemas com erros de mensuração e tem sido justificado, ainda, como uma forma de evitar, por um lado, a seleção ad hoc das proxies utilizadas como regressores e, por outro, eventuais problemas de multicolinearidade severa (Titman e Wessels, op. cit.).

\section{Métodos alternativos de regressão e outras variações da análise}

A exclusão de observações outliers, identificadas, por exemplo, com base nos resíduos Studentizados de regressões preliminares, não altera materialmente as conclusões, assim como a substituição, em todas as variáveis (excetuando-se as binárias) de seus valores "extremos" (maiores e menores) por valores "não-extremos" a eles adjacentes, procedimento conhecido como Winsorização. Como sugerem os resultados da aplicação de um procedimento de teste descrito por Wooldridge (2002, p. 581), as inferências não parecem ser significativamente influenciadas por algum viés de seleção amostral decorrente da quantidade significativa de observações faltantes em alguns regressores. Também a exclusão da amostra das empresas de controle estatal (nas quais pode haver ingerência política sobre a escolha dos gestores e outras decisões corporativas) não influencia materialmente as inferências da pesquisa. 
Finalmente, regressões estáticas similares às reportadas na Tabela A.6 foram computadas utilizando-se métodos de estimação mais tradicionais. Embora sejam menos justificáveis estatisticamente (como sugerem diferentes análises de diagnóstico), estes procedimentos são mais compatíveis com as estratégias empregadas em pesquisas anteriores nesta área. Especificamente, foram estimados modelos pelos métodos MQO (Mínimos Quadrados Ordinário), EF (Efeitos Fixos) e EA (Efeitos Aleatórios), além do método utilizado no estudo de Fama e French (Op. cit.), conhecido como estimador de Fama-MacBeth (FM). Para alguns regressores os resultados revelam-se, em certos casos, bastante diferentes daqueles comentados anteriormente. Não obstante, o relacionamento positivo e significante entre $C E$ e as medidas de alavancagem se mantém em todos os casos, mostrando-se robusto a variações significativas do método de estimação dos coeficientes. Como exemplo, em duas regressões estáticas estimadas por MQO, a primeira com um indicador de alavancagem contábil como variável dependente e a segunda com um indicador de alavancagem de mercado nesta posição, os coeficientes estimados para $C E$ são significantes no nível de $1 \%$ e aproximadamente iguais a 0,16 e 0,12 , respectivamente.

\subsection{Considerações Finais}

Nas seções anteriores foram empregadas diferentes estratégias de investigação empírica com o objetivo de examinar a hipótese de que os vieses cognitivos do excesso de confiança e do otimismo influenciam significativamente as decisões de financiamento das empresas. Especificamente, modelos comportamentais postulam que empresas geridas por indivíduos cognitivamente enviesados no sentido aqui descrito exibirão maior propensão ao endividamento, ceteris paribus, uma vez que os referidos gestores perceberão maiores benefícios e menores custos esperados associados à alavancagem financeira. Com base em pesquisas anteriores, de cunho teórico e empírico, argumentou-se que os vieses do otimismo e do excesso de confiança devem ser mais pronunciados no grupo dos gestores que são também "empreendedores" (isto é, gerem o próprio negócio) em comparação com o grupo dos executivos de carreira ou "não-empreendedores". Secundariamente, é também provável que estes vieses influenciem em alguma medida a propensão do gestor a manter ações da empresa que administra em sua carteira de investimentos pessoal. Tais argumentos fundamentam as definições operacionais para o construto comportamental utilizadas no trabalho, o qual oferece um dos primeiros testes da hipótese mencionada acima. 
$\mathrm{O}$ estudo preocupou-se centralmente com o atendimento e a verificação das condições que permitem a produção de inferências adequadas sobre os relacionamentos de interesse entre as variáveis. Em particular, os problemas potenciais de endogeneidade dos regressores aplicáveis à pesquisa foram extensivamente investigados. As análises de diagnóstico sugerem, por exemplo, que é importante modelar explicitamente a heterogeneidade não-observada (e invariante no tempo) das empresas e que a premissa de exogeneidade estrita dos regressores, adotada por métodos de estimação comumente utilizados, a exemplos dos procedimentos de Efeitos Fixos ou de Efeitos Aleatórios, provavelmente não é aceitável. Neste contexto, as características dos dados e os resultados dos diagnósticos apontam para a superioridade dos procedimentos de estimação apropriados para painéis curtos baseados no Método dos Momentos Generalizado (GMM), em especial o estimador GMM Sistêmico (Blundell e Bond, op. cit.), capaz de lidar simultaneamente com diferentes problemas de endogeneidade potencialmente relevantes. Por esta razão, os resultados obtidos com aplicações do referido estimador formam a base das inferências desta pesquisa. Não obstante, diversas estratégias alternativas de estimação foram aplicadas como forma de verificar a estabilidade dos resultados e sua sensibilidade a problemas específicos, tais como a presença de outliers na amostra.

Tanto nas formulações estáticas quanto dinâmicas o coeficiente estimado para $C E$ é positivo e geralmente significante nos níveis convencionais. Além disso, se a dinâmica da alavancagem for adequadamente representada por um modelo de ajustamento parcial em direção a um valor meta, como o mostrado em , o impacto de "longo prazo" de $C E$ sobre o nível de endividamento será similar em magnitude ao estimado nas formulações puramente estáticas. Tais resultados não parecem se dever à presença de observações extremas na amostra e nem a peculiaridades da especificação do modelo ou das definições operacionais das variáveis. A Tabela A.9, em particular, mostra que as conclusões são robustas a variações da definição operacional de $C E$. De fato, quando apenas os fundadores das empresas são classificados como empreendedores, excluindo-se da amostra os herdeiros, os coeficientes estimados para $C E$ são maiores em magnitude e mais significantes do que os obtidos previamente, o que confere suporte adicional à estratégia de identificação dos vieses cognitivos aqui enfocados.

É importante destacar, ainda, que os gestores classificados como excessivamente confiantes/otimistas são, em média, mais expostos ao risco idiossincrático do negócio que administram do que os demais, por possuírem (em média) uma maior riqueza investida em ações da própria empresa. De fato, a posse de muitas ações da própria empresa pode servir como uma proxy para os vieses cognitivos enfocados. Esta exposição, pode-se argumentar, tenderia, ceteris paribus, a tornar os referidos gestores mais cautelosos ou conservadores, levando-os, por exemplo, a escolher uma estrutura de financiamentos menos alavancada. Ademais, como argumentam Mishra e McConaughy (1999), o capital humano de gestores ligados à família fundadora do negócio está fortemente ligado ao empreendimento e, talvez, 
eles possam extrair benefícios da empresa não disponíveis para gestores não familiares, o que também justificaria o receio de perda do controle e uma conseqüente postura mais conservadora. Todavia, os resultados obtidos apontam precisamente no sentido contrário, uma vez que as empresas geridas por esses indivíduos tendem a ser mais alavancadas financeiramente. Tais evidências são compatíveis com a hipótese de que a suposta menor propensão a correr riscos destes gestores é mais do que compensada por sua percepção enviesada dos mesmos riscos motivada por seu otimismo e excesso de confiança. Na verdade, estes vieses cognitivos estimulam o indivíduo a se expor (em muitos casos exageradamente, do ponto vista racional) aos riscos idiossincráticos da empresa a priori.

Quanto aos demais candidatos a determinantes da estrutura de capital, a variável binária $A C U M$ apresentou os resultados mais estáveis e significantes. Este indicador representa o acúmulo ou não dos cargos de DP e PC da empresa pelo mesmo indivíduo. Os resultados sugerem claramente que, isolando-se outras influências, as empresas nas quais os referidos cargos são ocupados pela mesma pessoa tendem a ser substancialmente menos alavancadas, refletindo, possivelmente, a influência de padrões de governança, capturados em parte por $A C U M$, sobre suas condições de acesso aos mercados financeiros. Os coeficientes estimados para outros indicadores relacionados com a governança corporativa e concentração acionária também revelaram-se significantes em alguns modelos, ainda que de forma menos estável, sugerindo que diferenças sistemáticas nos padrões de governança e de estrutura de propriedade das empresas podem ser importantes para explicar as variações observadas em sua estrutura de capital.

Os coeficientes estimados para as proxies de tamanho ou porte da empresa apresentaram, em todos os casos, sinal positivo e revelaram-se estatisticamente significantes, pelo menos o nível de $10 \%$, na maior parte das regressões (em particular nas especificações estáticas). Estes resultados sugerem que empresas maiores tendem a ser mais alavancadas e são coerentes com as principais teorias de estrutura de capital. Resultados similares são reportados, por exemplo, por Rajan e Zingales (Op. cit.), Fama e French (Op. cit.) e Gaud et alii (Op. cit.). Há também evidência nos dados de um relacionamento negativo entre medidas de lucratividade e o grau de alavancagem das empresas, principalmente quando a variável de resposta é a alavancagem de mercado. Esta evidência, compatível com a teoria da pecking order, figura entre as regularidades empíricas mais freqüentemente reportadas neste campo de estudo (vide, por exemplo, Fama e French, op. cit., Terra e Mateus, 2005, Martin et alii, op. cit.). Por fim, assim como Fama e French (Op. cit.) e Frank e Goyal (2004), encontrou-se indícios de que as empresas que pagam dividendos são menos alavancadas, em média, ao passo que, similarmente ao reportado por Rajan e Zingales (Op. cit.), Gaud et alii (Op. cit.) e Frank e Goyal (2004), aquelas que apresentam maior grau de tangibilidade dos ativos tendem a ser mais alavancadas. Outros candidatos a determinantes da estrutura de capital não se mostraram consistentemente relevantes. 
Os resultados deste estudo empírico sugerem, de forma geral, que diferenças de opinião, estilo e de percepção da realidade motivadas por características pessoais dos gestores podem exercer impacto relevante sobre as decisões corporativas observadas. Ademais, algumas destas influências podem, ao que parece, ser previstas teoricamente. Há indícios, em particular, de que o otimismo/excesso de confiança dos gestores pode figurar como um importante determinante da estrutura de capital das empresas. Na mesma linha, os trabalhos empíricos de Malmendier e Tate (2002, 2003), utilizando dados norte-americanos, sugerem que estes vieses influenciam substancialmente certas decisões de investimento das empresas. Justificase, portanto, uma maior atenção a estas abordagens comportamentais, ainda pouco exploradas na literatura de finanças corporativas.

\section{Referências}

Alicke, M. D., Klotz, M. L., Breitenbecher, D. L., Yurak, T. J., \& Vredenburg, D. S. (1995). Personal contact, individuation, and the better-than-average effect. Journal of Personality and Social Psychology, 68(5):804-25.

Alpert, M. \& Raiffa, H. (1982). A progress report on the training of probability assessors. In Kahneman, D., Slovic, P., \& Tversky, A., editors, Judgment under Uncertainty: Heuristics and Biases. Cambridge University Press, England.

Arabsheibani, G., De Meza, D., Maloney, J., \& Pearson, B. (2000). And a vision appeared unto them of a great profit: Evidence of self-deception among the self-employed. Economic Letters, 67(1):35-41.

Arellano, M. (2003). Panel Data Econometrics. Oxford University Press, Oxford.

Arellano, M. \& Bond, S. R. (1991). Some tests of specification for panel data: Monte Carlo evidence and an application to employment equations. Review of Economic Studies, 58(194):277-97.

Baker, M., Ruback, R. S., \& Wurgler, J. A. (2004). Behavioral corporate finance: A survey. NBER Working Paper, n. 10863. Disponível em: http://www.nber.org/papers/w10863. Acesso em: 22/10/2004.

Baron, R. A. (1998). Cognitive mechanisms in entrepreneurship: Why and when entrepreneurs think differently than other people. Journal of Business Venturing, 13(4):275-94.

Baron, R. A. (2000a). Counterfactual thinking and venture formation: The potential effects of thinking about "what might have been". Journal of Business Venturing, 15(1):79-91.

Baron, R. A. (2000b). Psychological perspectives on entrepreneurship: Cognitive and social factors in entrepreneurs' success. Current Directions in Psychological Science, 9(1):15-18. 
Benartzi, S. (2001). Excessive extrapolation and the allocation of 401(k) accounts to company stock. Journal of Finance, 56(5):1747-64.

Bernardo, A. E. \& Welch, I. (2001). On the evolution of overconfidence and entrepreneurs. Journal of Economics and Management Strategy, 10(3):301-30.

Blundell, R. \& Bond, S. R. (1998). Initial conditions and moment restrictions in dynamic panel data models. Journal of Econometrics, 87(1):115-43.

Blundell, R., Bond, S. R., \& Windmeijer, F. (2000). Estimation in dynamic panel data models: Improving on the performance of the standard GMM estimator. In Advances in Econometrics: Nonstationary Panels, Panel Cointegration, and Dynamic Panels. Elsevier Science, New York. Baltagi, B. H. (org.).

Bowsher, C. G. (2002). On testing overidentifying restrictions in dynamic panel data models. Economic Letters, 77(2):211-20.

Brenner, L. A., Koehler, D. J., Liberman, V., \& Tversky, A. (1996). Overconfidence in probability and frequency judgments: A critical examination. Organizational Behavior and Human Decision Processes, 65(3):212-19.

Brito, R. D. \& Lima, M. R. (2005). A escolha da estrutura de capital sob fraca garantia legal: O caso do Brasil. Revista Brasileira de Economia, 59(2):177208.

Busenitz, L. W. \& Barney, J. B. (1997). Differences between entrepreneurs and managers in large organizations: Biases and heuristics in strategic decisionmaking. Journal of Business Venturing, 12(1):9-30.

Camerer, C. F. \& Lovallo, D. (1999). Overconfidence and excess entry: An experimental approach. American Economic Review, 89(1):306-18.

Chung, K. \& Pruitt, S. (1994). A simple approximation of Tobin's Q. Financial Management, 23(3):70-74.

Cooper, A. C., Woo, C. Y., \& Dunkelberg, W. C. (1988). Entrepreneurs' perceived chances for success. Journal of Business Venturing, 3(2):97-108.

De Bondt, W. F. M. \& Thaler, R. H. (1995). Financial decision-making in markets and firms: A behavioral perspective. In Handbooks in Operations Research and Management Science: Finance. Elsevier, Amsterdam. Jarrow, R. A., Maksimovic, R. \& Ziemba, W. T. (orgs.).

De Meza, D. \& Southey, C. (1996). The borrower's curse: Optimism, finance and entrepreneurship. Economic Journal, 106(435):375-86.

Evans, D. S. \& Leighton, L. S. (1989). Some empirical aspects of entrepreneurship. American Economic Review, 79(3):519-35. 
Fairchild, R. J. (2005). The effect of managerial overconfidence, asymmetric information, and moral hazard on capital structure decisions. Working Paper. Disponível em: http://ssrn.com/abstract=71184. Acesso em: 25/06/2005.

Fama, E. F. \& French, K. R. (2002). Testing trade-off and pecking order predictions about dividends and debt. Review of Financial Studies, 15(1):1-33.

Finkel, S. E. (1995). Causal analysis with panel data. (Sage University Paper series on Quantitative Applications in the Social Sciences, 07-105). Thousand Oaks: Sage.

Fischhoff, B. (1977). Knowing with certainty: The appropriateness of extreme confidence. Journal of Experimental Psychology: Human Perception and Performance, 3(4):552-64.

Frank, M. Z. \& Goyal, V. K. (2003). Testing the pecking order theory of capital structure. Journal of Financial Economics, 67(2):217-48.

Frank, M. Z. \& Goyal, V. K. (2004). Capital structure decisions: Which factors are reliably important? Working Paper. Disponível em: http://pacific.commerce.ubc.ca/frank/CapitalStructure.pdf. Acesso em $12 / 01 / 2005$.

French, K. R. \& Poterba, J. M. (1991). Investor diversification and international equity markets. American Economic Review, 81(2):222-6.

Gaud, P. (2005). The capital structure of swiss companies: An empirical analysis using dynamic panel data. European Financial Management, 11(1):51-69.

Gervais, S., Heaton III, J. B., \& Odean, T. (2003). Overconfidence, investment policy, and executive stock options. Rodney L. White Center for Financial Research Working Paper n. 15-02. Disponível em: http://ssrn.com/abstract=361200. Acesso em: 15/07/2004.

Gervais, S. \& Odean, T. (2001). Learning to be overconfident. Review of Financial Studies, 14(1):1-27.

Goel, A. M. \& Thakor, A. V. (2002). Do overconfident managers make better leaders? Working Paper. Disponível em: http://pages.stern.nyu.edu/ãgoel/papers/leader.pdf. Acesso em 16/11/2004.

Gomes, G. L. \& Leal, R. P. C. (2000). Determinantes da estrutura de capitais das empresas brasileiras com ações negociadas em bolsas de valores. In Leal, R. P. C., editor, Finanças Corporativas. Atlas, São Paulo.

Hackbarth, D. (2004). Managerial traits and capital structure decisions. Disponível em http://ssrn.com/abstract=362740. Acesso em 15/09/2004. 
Harris, M. \& Raviv, A. (1991). The theory of capital structure. Journal of Finance, 46(1):297-355.

Heaton III, J. B. (2002). Managerial optimism and corporate finance. Financial Management, 31(2):33-45.

Huberman, G. (2001). Familiarity breeds investment. Review of Financial Studies, 14(3):659-80.

Klotzle, M. C. \& Biagini, F. L. (2004). Fatores determinantes da estrutura de capital de empresas brasileiras. Revista de Economia e Administração, 3(3):253-71.

Kunda, Z. (1987). Motivated inference: Self-serving generation and evaluation of causal theories. Journal of Personality and Social Psychology, 53(4):636-47.

Landier, A. \& Thesmar, D. (2004). Financial contracting with optimistic entrepreneurs. Disponível em https://wpweb2k.gsia.cmu.edu/wfa/wfasecure/upload/631588_optimism2.pdf. Acesso em 07/08/2004.

Leal, R. P. C. \& Saito, R. (2003). Finanças corporativas no brasil. RAE-eletrônica, 2(2):1-15.

Lichtenstein, S., Fischhoff, B., \& Phillips, D. (1982). Calibration of probabilities: State of the art to 1980. In Judgment under Uncertainty: Heuristics and Biases. Cambridge University Press, Cambridge, England. Kahneman, D., Slovic, P. \& Tversky, A. (Org.).

Malmendier, U. \& Tate, G. A. (2002). CEO overconfidence and corporate investment. Disponível em http://ssrn.com/abstract=354387. Acesso em 19/07/2004.

Malmendier, U. \& Tate, G. A. (2003). Who makes acquisitions? CEO overconfidence and the market's reaction. Working Paper. Disponível em: http://ssrn.com/abstract=470788. Acesso em: 19/07/2004.

March, J. G. \& Shapira, Z. (1987). Managerial perspectives on risk and risk taking. Management Science, 33(11):1404-18.

Martin, D. M. L., Nakamura, W. T., Forte, D., Carvalho Filho, A., Costa, A. C. F., \& Cintra, A. (2005). Determinantes da estrutura de capital no mercado brasileiro: Análise de regressão com painel de dados no período 1999-2003. In $5^{\circ}$ Encontro Brasileiro de Finanças. Sociedade Brasileira de Finanças, São Paulo.

McConnell, J. J. \& Servaes, H. (1995). Equity ownership and the two faces of debt. Journal of Financial Economics, 39(1):131-58.

McKenna, F. P. (1993). It won't happen to me: Unrealistic optimism or illusion of control? British Journal of Psychology, 84(1):39-50. 
Miller, D. T. \& Ross, M. (1975). Self-serving biases in attribution of causality: Fact or fiction? Psychological Bulletin, 82(2):213-25.

Mishra, C. S. \& McConaughy, D. L. (1999). Founding family control and capital structure: The risk of loss of control and the aversion to debt. Entrepreneurship: Theory and Practice, 23(4):53.

Myers, S. C. (1984). The capital structure puzzle. Journal of Finance, 39(3):57592.

Myers, S. C. (2003). Financing of corporations. In Handbook of the Economics of Finance. North-Holland, New York. Constantinides, G., Harris, M. \& Stulz, R. M. (Orgs.).

Myers, S. C. \& Majluf, N. S. (1984). Corporate financing and investment decisions when firms have information that investors do not have. Journal of Financial Economics, 13(2):187-221.

Nisbett, R. E. \& Ross, L. (1980). Human Inference: Strategies and Shortcomings of Social Judgment. Prentice-Hall, New Jersey.

Palich, L. E. \& Bagby, D. R. (1995). Using cognitive theory to explain entrepreneurial risk-taking: Challenging conventional wisdom. Journal of Business Venturing, 10(6):425-38.

Perobelli, F. F. C. \& Famá, R. (2002). Determinantes da estrutura de capital: Aplicação a empresas de capital aberto brasileiras. Revista de Administração da Universidade de São Paulo, 37(3):33.

Petersen, M. A. (2005). Estimating standard errors in finance panel data sets: Comparing approaches. Kellogg Finance Department Working Paper, n. 329. Disponível em: http://ssrn.com/abstract=661481. Acesso em 19/03/2005.

Pinfold, J. F. (2001). The expectations of new business founders: The New Zealand case. Journal of Small Business Management, 39(3):279-85.

Procianoy, J. L. \& Schnorrenberger, A. (2004). A influência da estrutura de controle nas decisões de estrutura de capital das companhias brasileiras. Revista Brasileira de Economia, 58(1):122-46.

Rajan, R. G. \& Zingales, L. (1995). What do we know about capital structure? Some evidence from international data. Journal of Finance, 50(5):1421-41.

Rubinstein, M. (2001). Rational markets: Yes or no? The affirmative case. Financial Analysts Journal, 57(3):15-29.

Stulz, R. M. (1990). Managerial discretion and optimal financing policies. Journal of Financial Economics, 26(1):3-27. 
Svenson, O. (1981). Are we all less risky and more skillful than our fellow drivers? Acta Psychologica, 47(2):143-48.

Taylor, S. E. \& Brown, J. D. (1988). Illusion and well-being: A social psychological perspective on mental health. Psychological Bulletin, 103(2):193-210.

Terra, P. R. S. \& Mateus, C. (2005). The joint determination of capital structure and debt maturity: Empirical evidence from Latin America and Eastern Europe. In $5^{\circ}$ Encontro Brasileiro de Finanças. Sociedade Brasileira de Finanças, São Paulo.

Titman, S. \& Wessels, R. (1988). The determinants of capital structure choice. Journal of Finance, 43(1):1-19.

Treynor, J. L. \& Black, F. (1976). Corporate investment decisions. In Modern Developments in Financial Management. Praeger, New York. Myers, S. C.

Weinstein, N. D. (1980). Unrealistic optimism about future life events. Journal of Personality and Social Psychology, 39(5):806-20.

Weinstein, N. D. (1982). Unrealistic optimism about susceptibility to health problems. Journal of Behavioral Medicine, 5(4):441-60.

Wooldridge, J. M. (2002). Econometric Analysis of Cross Section and Panel Data. MIT Press, Cambridge, Massachusetts.

Zacharakis, A. L. \& Shepherd, D. A. (2001). The nature of information and overconfidence on venture capitalists' decision making. Journal of Business Venturing, 16(4):311-32. 


\section{Apêndice}

\section{Tabelas}

Tabela A.1

Definições operacionais das demais variáveis utilizadas

\begin{tabular}{|c|c|c|}
\hline Sigla & Nome da Variável & Definição \\
\hline IPVP & $\begin{array}{l}\text { Índice Preço sobre Valor Patri- } \\
\text { monial }\end{array}$ & Valor de mercado das ações sobre seu valor contábil \\
\hline $\bar{Q}$ & Q de Tobin & $\begin{array}{l}\text { Estimado pela aproximação proposta por Chung e Pruitt (1994): } \\
\qquad Q \text { de } \text { obin }_{i t} \cong \frac{V A_{i t}+D I V T_{i t}}{A_{i t}} \\
\text { VA - valor de mercado das açoes ordinárias e preferenciais; DIVT } \\
\text { - valor contábil da dívida, definido como passivo circulante mais } \\
\text { exigível a longo prazo mais estoques menos o ativo circulante; A } \\
\text { - ativo total }\end{array}$ \\
\hline VMAT & $\begin{array}{l}\text { Índice valor de mercado sobre } \\
\text { patrimônio líquido } \\
\text { Îndice valor de mercado sobre } \\
\text { ativo }\end{array}$ & $\begin{array}{l}\text { Valor total de mercado das ações sobre patrimônio líquido } \\
\qquad V M A T_{i t} \equiv \frac{A_{i t}-P L_{i t}+V A_{i t}}{A_{i t}} \\
\text { VA - valor de mercado das ações ordinárias e preferenciais; PL - } \\
\text { patrimônio líquido; A - ativo total }\end{array}$ \\
\hline$\overline{\mathrm{CR}}$ & Crescimento & $\begin{array}{l}\text { Taxa de variação percentual acumulada da receita líquida nos três } \\
\text { últimos anos }\end{array}$ \\
\hline $\mathrm{dA}$ & Taxa de variação do ativo & Variação percentual do ativo entre os anos $t-1 \mathrm{e} t$ \\
\hline LAJIRDA & $\begin{array}{l}\text { Lucratividade com base no } \\
\text { LAJIRDA }\end{array}$ & $\begin{array}{l}\text { Lucro antes de juros, impostos, depreciação e amortização sobre } \\
\text { ativo }\end{array}$ \\
\hline $\begin{array}{c}\text { LOPA } \\
\end{array}$ & $\begin{array}{l}\text { Lucratividade com base no Lu- } \\
\text { cro Operacional Próprio }\end{array}$ & Lucro Operacional Próprio sobre ativo \\
\hline LOA & Lucratividade com base no LO & Lucro Operacional sobre ativo \\
\hline Tang & Tangibilidade & $\begin{array}{l}\text { Ativo imobilizado bruto (antes da depreciação) somado ao estoque } \\
\text { sobre ativo }\end{array}$ \\
\hline $\operatorname{lnR}$ ou $\ln \mathrm{A}$ & Tamanho & Logaritmo natural da receita líquida ou do ativo total \\
\hline SING & Singularidade & Despesas de vendas sobre receita líquida \\
\hline$\overline{B E T A}$ ou DPA & Volatilidade & $\begin{array}{l}\text { Beta da ação utilizando uma janela de } 60 \text { semanas (BETA) ou desvio } \\
\text { padrão dos retornos diários da ação ao longo do ano (DPA) }\end{array}$ \\
\hline BFED & Benefícios fiscais extra-dívida & Depreciação e amortização do exercício sobre ativo \\
\hline PAYOUT & Índice de payout da empresa & Dividendos pagos por ação sobre lucro líquido por ação \\
\hline DIVA & Dividendos sobre ativo & Dividendos pagos no ano sobre ativo \\
\hline$\overline{\text { DIV }}$ & Distribuição de dividendos & $\begin{array}{l}\text { Variável binária que assume valor igual a um se a empresa distribuiu } \\
\text { dividendo no ano e zero caso contrário }\end{array}$ \\
\hline CON e TOT & $\begin{array}{l}\text { Concentração do direito de } \\
\text { voto e da propriedade do aci- } \\
\text { onista controlador }\end{array}$ & $\begin{array}{l}\text { Percentual de ações ordinárias (CON) ou percentual do total de ações } \\
\text { (TOT) em posse do(s) acionista(s) controlador(es) da empresa }\end{array}$ \\
\hline IDENT1... IDENT6 & Tipo do acionista controlador & $\begin{array}{l}\text { Seis variáveis binárias informando se o controlador é privado nacio- } \\
\text { nal, estatal, estrangeiro, família, banco ou fundo de pensão }\end{array}$ \\
\hline$\overline{\mathrm{ACUM}}$ & $\begin{array}{l}\text { Acúmulo dos cargos de DP e } \\
\text { PC pelo mesmo indivíduo }\end{array}$ & $\begin{array}{l}\text { Variável binária que assume valor igual a um se há acúmulo } \\
\text { dos cargos de Diretor Presidente e Presidente do Conselho de } \\
\text { Administração pela mesma pessoa e assume valor igual zero caso } \\
\text { contrário }\end{array}$ \\
\hline TAMCA & Tamanho do CA & Número de membros do Conselho de Administração \\
\hline INDCA & Grau de independência do CA & $\begin{array}{l}\text { Razão entre o número de conselheiros que não são executivos da em- } \\
\text { presa e o número total de membros do Conselho de Administração }\end{array}$ \\
\hline ADR & Emissão de ADR & $\begin{array}{l}\text { Variável binária que assume valor igual a um se a empresa emitiu } \\
\text { ADRs e zero caso contrário }\end{array}$ \\
\hline BOV & $\begin{array}{l}\text { Adesão da empresa aos níveis } \\
\text { de governança da Bovespa }\end{array}$ & $\begin{array}{l}\text { Variável binária que assume valor igual a um se a empresa aderiu aos } \\
\text { Níveis Diferenciados de Governança Corporativa da Bovespa e zero } \\
\text { caso contrário }\end{array}$ \\
\hline IND1... IND17 & Dummies setoriais & $\begin{array}{l}\text { Dezessete variáveis binárias atribuindo valor um para as empresas } \\
\text { pertencentes a um setor específico e zero para as pertencentes aos } \\
\text { demais setores (adota-se o critério de classificação da Economática, } \\
\text { composto por vinte categorias, três das quais não tiveram represen- } \\
\text { tante na amostra) }\end{array}$ \\
\hline $\mathrm{ANO}(1) \ldots \mathrm{ANO}(6)$ & Dummies de ano & $\begin{array}{l}\text { Variáveis binárias } A N O_{t} \text { definidas como } A N O_{t}=1 \text { no } t \text { - } \\
\text { ésimo ano e } A N O_{t}=0 \text { caso contrário, com } t=1, \ldots, 6 \\
\text { (1998 a 2003) }\end{array}$ \\
\hline
\end{tabular}


Tabela A.2

Setores de atividade das empresas da amostra

\begin{tabular}{l|c}
\hline \multicolumn{1}{c|}{ Setor } & Percentual de empresas no setor (\%) \\
\hline Agro e Pesca & 0,65 \\
Alimentos e Bebidas & 5,88 \\
Comércio & 3,27 \\
Construção & 3,27 \\
Eletroeletrônicos & 3,27 \\
Energia Elétrica & 13,73 \\
Minerais não Metálicos & 1,31 \\
Mineração & 1,96 \\
Máquinas Industriais & 4,58 \\
Outros & 11,11 \\
Papel e Celulose & 3,92 \\
Petróleo e Gás & 3,27 \\
Química & 8,5 \\
Siderurgia e Metalurgia & 9,8 \\
Telecomunicações & 11,11 \\
Têxtil & 6,54 \\
Veículos e Peças & 7,84 \\
\hline
\end{tabular}

Tabela A.3

Natureza do controlador das empresas da amostra

\begin{tabular}{l|cccccc}
\hline Natureza do controlador & \multicolumn{7}{|c}{ Percentual de empresas (\%) em cada ano } \\
& 1998 & 1999 & 2000 & 2001 & 2002 & 2003 \\
\hline Estatal & 7,48 & 7,43 & 7,28 & 7,19 & 7,19 & 7,19 \\
Familiar & 48,3 & 47,97 & 46,36 & 46,41 & 46,41 & 46,41 \\
Fundo de Pensão & 5,44 & 5,41 & 5,3 & 5,23 & 5,23 & 5,23 \\
Privada Estrangeira & 21,77 & 22,3 & 23,18 & 23,53 & 23,53 & 23,53 \\
Privada Nacional & 17,01 & 16,89 & 17,88 & 17,65 & 17,65 & 17,65 \\
\hline
\end{tabular}


Tabela A.4

Estatísticas descritivas das variáveis

\begin{tabular}{|c|c|c|c|c|c|}
\hline Variável & Média & $\begin{array}{l}\text { Desvio } \\
\text { Padrão }\end{array}$ & $\begin{array}{c}1^{0} \\
\text { Quartil }\end{array}$ & Mediana & $\begin{array}{c}3^{0} \\
\text { Quartil }\end{array}$ \\
\hline ALAV. - $E / A$ & 0,359 & 0,342 & 0,184 & 0,308 & 0,453 \\
\hline ALAV. - $E /(V M A+A-P L)$ & 0,323 & 0,206 & 0,174 & 0,317 & 0,46 \\
\hline ALAV. - $E L P / A$ & 0,2 & 0,228 & 0,053 & 0,156 & 0,273 \\
\hline ALAV. $-E L P /(V M A+A-P L)$ & 0,174 & 0,14 & 0,058 & 0,152 & 0,263 \\
\hline Preço sobre valor patr. - $I P V P$ & 1,063 & 1,455 & 0,372 & 0,659 & 1,24 \\
\hline Q de Tobin & 0,68 & 0,431 & 0,411 & 0,623 & 0,833 \\
\hline Valor ações sobre PL - VAPL & 1,139 & 2,511 & 0,382 & 0,678 & 1,166 \\
\hline Valor merc. sobre at. - $V M A T$ & 1 & 0,639 & 0,753 & 0,91 & 1,066 \\
\hline Cresc. da Receita - $C R$ & 0,004 & 0,607 & $-0,03$ & 0,072 & 0,172 \\
\hline Variação do ativo - $d A$ & 0,008 & 0,229 & $-0,074$ & 0,008 & 0,1 \\
\hline Lucratividade - $l A J I R D A$ & 0,149 & 0,118 & 0,08 & 0,136 & 0,207 \\
\hline Lucratividade - $L O P A$ & 0,094 & 0,105 & 0,041 & 0,085 & 0,14 \\
\hline Lucratividade - $L O A$ & 0,021 & 0,162 & $-0,023$ & 0,031 & 0,088 \\
\hline Tangibilidade - TANG & 1,051 & 0,51 & 0,758 & 0,988 & 1,239 \\
\hline Tamanho (Receita) - $\ln R$ & 5,934 & 0,693 & 5,537 & 5,982 & 6,384 \\
\hline Tamanho (Ativo) - $\ln A$ & 14,117 & 1,644 & 13,209 & 14,105 & 15,106 \\
\hline Singularidade - SING & 0,089 & 0,077 & 0,028 & 0,077 & 0,134 \\
\hline Volatilidade - $B E T A$ & 0,533 & 0,418 & 0,242 & 0,477 & 0,772 \\
\hline Volatilidade - $D P A$ & 0,767 & 0,568 & 0,452 & 0,61 & 0,821 \\
\hline Benf. fisc. extra dív. - $B F E D$ & 0,046 & 0,031 & 0,027 & 0,038 & 0,056 \\
\hline Dividendos - PAYOUT & 83,485 & 1064,961 & 0 & 27,733 & 50,38 \\
\hline Dividendos - $D I V A$ & 0,02 & 0,036 & 0 & 0,012 & 0,027 \\
\hline Dividendos - $D I V$ & 0,723 & 0,448 & 0 & 1 & 1 \\
\hline Governança - $C O N$ & 0,742 & 0,201 & 0,573 & 0,766 & 0,928 \\
\hline Governança - TOT & 0,508 & 0,234 & 0,316 & 0,491 & 0,683 \\
\hline Governança - TAMCA & 7,15 & 3,1 & 5 & 7 & 9 \\
\hline Governança - INDCA & 0,822 & 0,153 & 0,714 & 0,833 & 1 \\
\hline
\end{tabular}


Tabela A.5

Determinantes da estrutura de capital: regressões utilizando o método GMM-Sistêmico com modelos dinâmicos

\begin{tabular}{|c|c|c|c|c|}
\hline \multirow[b]{2}{*}{ Regressores } & \multicolumn{2}{|c|}{ Alavancagem contábil } & \multicolumn{2}{|c|}{ Alavancagem de mercado } \\
\hline & GMM-Sis & Coef. transf. & GMM-Sis & Coef. transf. \\
\hline$A L A V_{t-1}$ & 0,6614 *** $(0,076)$ & & 0,8041 *** $(0,044)$ & \\
\hline$C E$ & 0,0521 *** $(0,018)$ & 0,1538 & $0,0250^{* *} \quad(0,011)$ & 0,1278 \\
\hline Preço/valor patrim. & $-0,0016 \quad(0,005)$ & $-0,0048$ & $-0,0031 \quad(0,003)$ & $-0,0156$ \\
\hline Op. de crescimento & $0,0085 \quad(0,010)$ & 0,025 & $(0,007)$ & 0,0164 \\
\hline Lucratividade & $-0,1961^{*} \quad(0,115)$ & $-0,5792$ & $-0,2133 * *(0,085)$ & $-1,0885$ \\
\hline Volatilidade & 0,0237 & 0,0699 & $0,0448 * * * *(0,017)$ & 0,2288 \\
\hline Ben. Fisc. extra-dív. & $-0,6282 \quad(0,500)$ & $-1,8551$ & $-0,3361$ & $-1,7154$ \\
\hline Tangibilidade & $0,0812^{* *}(0,032)$ & 0,2398 & $0,0513 * * *(0,019)$ & 0,2617 \\
\hline Tamanho & $0,0320^{*} \quad(0,018)$ & 0,0944 & $(0,013)$ & 0,0267 \\
\hline Singularidade & 0,0026 & 0,0076 & $(0,090)$ & 0,1542 \\
\hline Dividendos & $-0,0465$ & $-0,1372$ & $-0,0107 \quad(0,027)$ & $-0,0544$ \\
\hline$C O N$ & $-0,1216^{*} \quad(0,069)$ & $-0,359$ & $-0,0563 \quad(0,045)$ & $-0,2872$ \\
\hline$A C U M$ & $-0,0718^{* * *}(0,016)$ & $-0,2121$ & $-0,0354 * * *(0,012)$ & $-0,1807$ \\
\hline$A D R$ & $-0,0111$ & $-0,0327$ & $-0,0074$ & $-0,0379$ \\
\hline$B O V$ & 0,0271 & 0,0802 & $(0,011)$ & 0,0471 \\
\hline Dummies Ano & SIM & - & SIM & - \\
\hline Número de obs. & 452 & & 456 & \\
\hline$J$ de Hansen & $95,03(91 ; 0,366)$ & & $101,96(91 ; 0,203)$ & \\
\hline$m 1$ & $-3,19(0,001)$ & & $-3,94(0,000)$ & \\
\hline$m 2$ & $0,00(0,998)$ & & $-0,39(0,697)$ & \\
\hline
\end{tabular}

A variável dependente utilizada na regressão reportada na coluna 2 é a alavancagem contábil da empresa, definida como a razão entre suas dívidas financeiras totais $(E)$ e seu ativo total contábil $(A)$. A regressão reportada na coluna 4 utiliza como variável dependente a alavancagem de mercado, definida como $E /(V M A+A-P L)$, sendo $V M A$ o valor de mercado das ações e $P L$ o valor contábil do patrimônio líquido da empresa (vide Seção 3.6).

Os regressores são: a primeira defasagem da variável de resposta $\left(A L A V_{t-1}\right), C E$ (vide definição na Seção 3.6, terceiro parágrafo), $I P V P$ (Preco/valor patrimonial), $C R$ (oportunidades futuras de crescimento), $L A J I R D A$ (lucratividade), $B E T A$ (volatilidade), $B F E D$ (benefícios fiscais extra-dívida), TANG (tangibilidade), $\ln R$ (tamanho), $S I N G$ (singularidade), $D I V$ (dividendos), $C O N$ (concentração dos direitos de voto), ACUM (acúmulo dos cargos de DP e PC), $A D R$ (emissão de ADR), $B O V$ (adesão aos níveis diferenciados de governança da Bovespa) um conjunto de variáveis indicadoras de ano. As definições operacionais constam da Tabela A.1.

O estimador utilizado é o GMM-Sis de um estágio aplicando às variáveis a transformação de Primeira Diferença (PD). Utilizou-se como instrumentos as transformações de PD defasadas em um período e as defasagens apropriadas a partir de $t-2$ de $A L A V$ e dos regressores $I P V P$, $L A J I R D A, B F E D, B E T A, D I V$ e $C O N$. Assume-se que os demais regressores são estritamente exógenos.

$\mathrm{O}$ erro-padrão de cada coeficiente figura entre parênteses. $* * *, * * \mathrm{e} *$ denotam a significância estatística da estimativa nos níveis de $1 \%, 5 \%$ e $10 \%$, respectivamente. Os erros-padrão foram calculados utilizando-se os dados agrupados por empresa e são robustos a formas arbitrárias de heterocedasticidade e autocorrelação dos erros do modelo. Nas colunas 3 e 5 da tabela figuram os coeficientes transformados, obtidos pela divisão de cada coeficiente por $1-\hat{\alpha}$, sendo $\hat{\alpha}$ o coeficiente estimado para $A L A V_{t-1}$.

O teste da estatística $J$ de Hansen é uma versão robusta (a formas arbitrárias de autocorrelação e heterocedasticidade dos erros) do mais conhecido teste de restrições de sobre-identificação de Sargan. $m 1$ e $m 2$ referem-se aos testes de autocorrelação de primeira e segunda ordem, respectivamente, aplicados aos resíduos transformados por PD (Arellano e Bond, op. cit.). Para o teste de Hansen reporta-se a estatística do teste e, entre parênteses, o número de graus de liberdade e seu nível descritivo ( $p$-value), respectivamente. Para os testes $m 1$ e $m 2$ reporta-se a estatística do teste e, entre parênteses, o p-value correspondente. 


\section{Tabela A.6}

Determinantes da estrutura de capital: regressões utilizando o método GMM-Sistêmico com modelos estáticos

\begin{tabular}{|c|c|c|}
\hline Regressores & $\begin{array}{c}\text { Alavancagem contábil } \\
\text { GMM-Sis }\end{array}$ & $\begin{array}{c}\text { Alavancagem de mercado } \\
\text { GMM-Sis }\end{array}$ \\
\hline$C E$ & $0,1327 * * *(0,041)$ & $\overline{0,0932 * * *(0,029)}$ \\
\hline Preço/valor patrim. & $0,0087 \quad(0,010)$ & $-0,0130 * *(0,006)$ \\
\hline Op. de crescimento & $0,0143 * \quad(0,008)$ & 0,0051 \\
\hline Lucratividade & $-0,1042$ & $-0,4131 * *(0,173)$ \\
\hline Volatilidade & $0,0484 \quad(0,041)$ & 0,0308 \\
\hline Ben. Fisc. extra-dív. & $0,5369 \quad(0,773)$ & 0,2365 \\
\hline Tangibilidade & $(0,052)$ & 0,0431 \\
\hline Tamanho & $0,1089 * * *(0,031)$ & $0,0684 * * \quad(0,028)$ \\
\hline Singularidade & $-0,3564 * \quad(0,215)$ & $-0,3194$ \\
\hline Dividendos & $-0,1118^{* *} \quad(0,056)$ & $-0,0655$ \\
\hline$C O N$ & $-0,2597$ & $-0,1668$ \\
\hline$A C U M$ & $-0,1396^{* * *}(0,032)$ & $-0,1201 * * *(0,026)$ \\
\hline$A D R$ & $-0,1166^{* *}(0,048)$ & $-0,0899 * * \quad(0,044)$ \\
\hline$B O V$ & $(0,042)$ & 0,0577 \\
\hline Dummies Ano & SIM & SIM \\
\hline Número de obs. & 524 & 526 \\
\hline$J$ de Hansen & $81,97(78 ; 0,357)$ & $80,31(78 ; 0,406)$ \\
\hline$m 1$ & $-2,32(0,020)$ & $-1,89(0,058)$ \\
\hline$m 2$ & $-1,99(0,047)$ & $-1,45(0,148)$ \\
\hline
\end{tabular}

A variável dependente utilizada na regressão reportada na coluna 2 é a alavancagem contábil da empresa, definida como a razão entre suas dívidas financeiras totais $(E)$ e seu ativo total contábil $(A)$. A regressão reportada na coluna 3 utiliza como variável dependente a alavancagem de mercado, definida como $E /(V M A+A-P L)$, sendo $V M A$ o valor de mercado das ações e $P L$ o valor contábil do patrimônio líquido da empresa (vide Seção 3.6).

Os regressores são: $C E$ (vide definição na Seção 3.6. terceiro parágrafo), $I P V P$ (Preço/valor patrimonial), $C R$ (oportunidades futuras de crescimento), LAJIRDA (lucratividade), BETA (volatilidade), BFED (benefícios fiscais extra-dívida), $T A N G$ (tangibilidade), $\ln R$ (tamanho), $S I N G$ (singularidade), $D I V$ (dividendos), $C O N$ (concentração dos direitos de voto), $A C U M$ (acúmulo dos cargos de DP e PC), $A D R$ (emissão de ADR), BOV (adesão aos níveis diferenciados de governança da Bovespa) e um conjunto de variáveis indicadoras de ano. As definições operacionais constam da Tabela A.1.

O estimador utilizado é o GMM-Sis de um estágio aplicando às variáveis a transformação de Primeira Diferença (PD). Utilizou-se como instrumentos as transformações de PD defasadas em um período e as defasagens apropriadas a partir de $t-2$ dos regressores IPVP,LAJIRDA, BFED, $B E T A, D I V$ e $C O N$. Assume-se que os demais regressores são estritamente exógenos.

$\mathrm{O}$ erro-padrão de cada coeficiente figura entre parênteses. ***, ** e * denotam a significância estatística da estimativa nos níveis de $1 \%, 5 \%$ e $10 \%$, respectivamente. Os erros-padrão foram calculados utilizando-se os dados agrupados por empresa e são robustos a formas arbitrárias de heterocedasticidade e autocorrelação dos erros do modelo.

O teste da estatística $J$ de Hansen é uma versão robusta (a formas arbitrárias de autocorrelação e heterocedasticidade dos erros) do mais conhecido teste de restrições de sobre-identificação de Sargan. $m 1$ e $m 2$ referem-se aos testes de autocorrelação de primeira e segunda ordem, respectivamente, aplicados aos resíduos transformados por PD (Arellano e Bond, op. cit.). Para o teste de Hansen reporta-se a estatística do teste e, entre parênteses, o número de graus de liberdade e seu nível descritivo ( $p$-value), respectivamente. Para os testes $m 1$ e $m 2$ reporta-se a estatística do teste e, entre parênteses, o $p$-value correspondente. 


\section{Tabela A.7}

Determinantes da estrutura de capital: regressões utilizando o método GMM-Sistêmico com modelos estáticos (especificação alternativa)

\begin{tabular}{|c|c|c|}
\hline Regressores & $\begin{array}{c}\text { Alavancagem contábil } \\
\text { GMM-Sis }\end{array}$ & $\begin{array}{c}\text { Alavancagem de mercado } \\
\text { GMM-Sis }\end{array}$ \\
\hline$C E$ & $0,1849^{* *}(0,094)$ & $0,1297 * *(0,067)$ \\
\hline Preço/valor patrim. & $0,0011 \quad(0,012)$ & $-0,0201 * *(0,009)$ \\
\hline Op. de crescimento & $0,0179 \quad(0,025)$ & $0,0014 \quad(0,021)$ \\
\hline Lucratividade & $-0,2269 \quad(0,246)$ & $-0,4087 *(0,211)$ \\
\hline Volatilidade & $0,0139 \quad(0,051)$ & $-0,0053 \quad(0,045)$ \\
\hline Ben. Fisc. extra-dív. & $0,6013 \quad(0,787)$ & $0,5311 \quad(0,839)$ \\
\hline Tangibilidade & $0,0619 \quad(0,077)$ & 0,0497 \\
\hline Tamanho & $0,1181 * *(0,060)$ & $0,1039 * *(0,050)$ \\
\hline Singularidade & $0,5045 \quad(0,483)$ & $0,5238 \quad(0,413)$ \\
\hline Dividendos & $-0,1237^{*} \quad(0,075)$ & $-0,1027 * \quad(0,054)$ \\
\hline$C O N$ & $-0,1522 \quad(0,167)$ & 0,0395 \\
\hline$A C U M$ & $-0,1518 * * *(0,056)$ & $-0,1561 * * *(0,047)$ \\
\hline$A D R$ & $-0,1844 * *(0,085)$ & $-0,1613 * *(0,076)$ \\
\hline$B O V$ & $0,0309 \quad(0,091)$ & $0,0260 \quad(0,069)$ \\
\hline Dummies Ano & SIM & SIM \\
\hline Número de obs. & 524 & 526 \\
\hline J de Hansen & $99,60(100 ; 0,429)$ & $107,29(100 ; 0,291)$ \\
\hline$m 1$ & $-2,34(0,019)$ & $-2,35(0,019)$ \\
\hline$m 2$ & $-1,73(0,083)$ & $-0,99(0,321)$ \\
\hline
\end{tabular}

A variável dependente utilizada na regressão reportada na coluna 2 é a alavancagem contábil da empresa, definida como a razão entre suas dívidas financeiras totais $(E)$ e seu ativo total contábil $(A)$. A regressão reportada na coluna 3 utiliza como variável dependente a alavancagem de mercado, definida como $E /(V M A+A-P L)$, sendo $V M A$ o valor de mercado das ações e $P L$ o valor contábil do patrimônio líquido da empresa (vide Seção 3.6)

Os regressores são: $C E$ (vide definição na Seção 3.6, terceiro parágrafo), $I P V P$ (Preço/valor patrimonial), $C R$ (oportunidades futuras de crescimento), LAJIRDA (lucratividade), BET A (volatilidade), BFED (benefícios fiscais extra-dívida), $T A N G$ (tangibilidade), $\ln R$ (tamanho), $S I N G$ (singularidade), $D I V$ (dividendos), $C O N$ (concentração dos direitos de voto), $A C U M$ (acúmulo dos cargos de $\mathrm{DP}$ e PC), $A D R$ (emissão de ADR), $B O V$ (adesão aos níveis diferenciados de governança da Bovespa) e um conjunto de variáveis indicadoras de ano. As definições operacionais constam da Tabela A.1.

O estimador utilizado é o GMM-Sis de um estágio aplicando às variáveis a transformação de Primeira Diferença (PD). Assume-se que os erros dos modelos seguem um processo de média móvel de ordem 1 (MA(1)) e, portanto, apresentam autocorrelação de primeira ordem. Utilizou-se como instrumentos as transformações de PD defasadas em dois períodos e as defasagens apropriadas a partir de $t-3$ de todos os regressores com exceção das variáveis indicadoras de ano, tratadas como estritamente exógenas.

$\mathrm{O}$ erro-padrão de cada coeficiente figura entre parênteses. $* * *, * * \mathrm{e} *$ denotam a significância estatística da estimativa nos níveis de 1\%,5\% e 10\%, respectivamente. Os erros-padrão foram calculados utilizando-se os dados agrupados por empresa e são robustos a formas arbitrárias de heterocedasticidade e autocorrelação dos erros do modelo.

O teste da estatística $J$ de Hansen é uma versão robusta (a formas arbitrárias de autocorrelação e heterocedasticidade dos erros) do mais conhecido teste de restrições de sobre-identificação de Sargan. $m 1$ e $m 2$ referem-se aos testes de autocorrelação de primeira e segunda ordem, respectivamente, aplicados aos resíduos transformados por PD (Arellano e Bond, op. cit.). Para o teste de Hansen reporta-se a estatística do teste e, entre parênteses, o número de graus de liberdade e seu nível descritivo ( $p$-value), respectivamente. Para os testes $m 1$ e $m 2$ reporta-se a estatística do teste e, entre parênteses, o $p$-value correspondente. 
Tabela A.8

Definições operacionais de $C E$

\begin{tabular}{|c|c|c|}
\hline Variável & $C E=1$ & $C E=0$ \\
\hline$C E_{1}$ & $\begin{array}{l}\text { Se o DP ou o PC é fundador ou herdeiro do } \\
\text { negócio }\end{array}$ & Caso contrário \\
\hline$C E_{2}$ & Se o DP ou o PC é o fundador do negócio & $\begin{array}{l}\text { Se nem o DP nem o PC é fundador ou herdeiro } \\
\text { do negócio }\end{array}$ \\
\hline$C E_{3}$ & Se o DP é fundador ou herdeiro do negócio & $\begin{array}{l}\text { Se nem o DP nem o PC é fundador ou herdeiro } \\
\text { do negócio }\end{array}$ \\
\hline$C E_{4}$ & Se o PC é fundador ou herdeiro do negócio & $\begin{array}{l}\text { Se nem o DP nem o PC é fundador ou herdeiro } \\
\text { do negócio }\end{array}$ \\
\hline$C E_{5}$ & $\begin{array}{l}\text { Se o DP ou o PC possui mais do que } 50 \% \text { das } \\
\text { ações ordinárias da empresa }\end{array}$ & Caso contrário \\
\hline$C E_{6}$ & $\begin{array}{l}\text { Se o DP ou o PC possui uma "riqueza inves- } \\
\text { tida" superior à mediana amostral }\end{array}$ & Caso contrário \\
\hline
\end{tabular}

Tabela A.9

Coeficientes estimados para a variável $C E$ com diferentes definições operacionais

\begin{tabular}{l|cr|rr}
\hline & \multicolumn{3}{|c|}{ Alavancagem contábil } & \multicolumn{2}{c}{ Alavancagem de mercado } \\
Regressores & GMM-Sis (Estático) & GMM-Sis (Dinâmico) & GMM-Sis (Estático) & GMM-Sis (Dinâmico) \\
\hline$C E_{1}$ & $0,1327^{* * *}(0,041)$ & $0,0521^{* * *}(0,018)$ & $0,0932^{* * *}(0,029)$ & $0,0250^{* *}(0,011)$ \\
$C E_{2}$ & $0,1345^{* *}(0,056)$ & $0,0649 * * *(0,023)$ & $0,1062^{* * * *}(0,037)$ & $0,0391^{* *}(0,016)$ \\
$C E_{3}$ & $0,1032^{* *}(0,046)$ & $0,0473^{* *}(0,021)$ & $0,1084^{* * *}(0,038)$ & $0,0302^{* *}(0,015)$ \\
$C E_{4}$ & $0,1345^{* * *}(0,040)$ & $0,0547^{* * *}(0,018)$ & $0,0939^{* * *}(0,029)$ & $0,0283^{* *}(0,011)$ \\
$C E_{5}$ & $0,0623^{*}(0,036)$ & $0,0363^{* *}(0,015)$ & $0,0506 \quad(0,034)$ & $0,0203^{* *}(0,010)$ \\
$C E_{6}$ & $0,1259^{* * *}(0,039)$ & $0,0561^{* * *}(0,019)$ & $0,0799^{* * *}(0,029)$ & $0,0322^{* * * *}(0,013)$ \\
\hline
\end{tabular}

A variável dependente utilizada nas regressões reportadas nas colunas 2 e 3 é a alavancagem contábil da empresa, definida como a razão entre suas dívidas financeiras totais $(E)$ e seu ativo total contábil $(A)$. As regressões reportadas nas colunas 4 e 5 utilizam como variável dependente a alavancagem de mercado, definida como $E /(V M A+A-P L)$, sendo $V M A$ o valor de mercado das ações e $P L$ o valor contábil do patrimônio líquido da empresa (vide Seção 3.6).

Cada linha da tabela mostra os coeficientes estimados para $C E$ e seus erros-padrão em regressões diferentes utilizando o mesmo conjunto de variáveis de controle. As definições operacionais de $C E_{1}, C E_{2}, \ldots, C E_{6}$ constam da Tabela A.8.

O estimador utilizado é o GMM-Sis de um estágio aplicando às variáveis a transformação de Primeira Diferença (PD). Nas colunas 2 e 4 as especificações são estáticas e idênticas às reportadas na Tabela A.6. Nas colunas 3 e 5 as regressões baseiam-se em modelos dinâmicos com as mesmas especificações reportadas na Tabela A.5.

Para os modelos estáticos, as variáveis de controle são: $I P V P$ (Preço/valor patrimonial), $C R$ (oportunidades futuras de crescimento), LAJIRDA (lucratividade), BETA (volatilidade), $B F E D$ (benefícios fiscais extra-dívida), TANG (tangibilidade), $\ln R$ (tamanho), $S I N G$ (singularidade), $D I V$ (dividendos), $C O N$ (concentração dos direitos de voto), $A C U M$ (acúmulo dos cargos de DP e PC), $A D R$ (emissão de ADR), $B O V$ (adesão aos níveis diferenciados de governança da Bovespa) e um conjunto de variáveis indicadoras de ano. As definições operacionais constam da Tabela A.1. Nas especificações dinâmicas inclui-se entre os regressores a primeira defasagem da variável de resposta $\left(A L A V_{t-1}\right)$.

$\mathrm{O}$ erro-padrão de cada coeficiente figura entre parênteses. $* * * * * *$ e $*$ denotam a significância estatística da estimativa nos níveis de $1 \%, 5 \%$ e $10 \%$, respectivamente. Os erros-padrão foram calculados utilizando-se os dados agrupados por empresa e são robustos a formas arbitrárias de heterocedasticidade e autocorrelação dos erros do modelo. 